Article

\title{
Urban Metabolism of Three Cities in Jing-Jin-Ji Urban Agglomeration, China: Using the MuSIASEM Approach
}

\author{
Xiaoyue Wang, Shuyao Wu and Shuangcheng $\mathrm{Li}^{*}$ \\ The Key Laboratory for Earth Surface Processes, Ministry of Education, College of Urban and Environmental \\ Sciences, Peking University, Beijing 100871, China; 1501214750@pku.edu.cn (X.W.); \\ wushuyaoalbert@pku.edu.cn (S.W.) \\ * Correspondence: scli@urban.pku.edu.cn; Tel.: +86-10-6276-7428
}

Received: 12 June 2017; Accepted: 18 August 2017; Published: 21 August 2017

\begin{abstract}
Urban problems-such as resources depletion, environment pollution and waste generation-usually occur during rapid urbanisation processes, especially in mega-urban agglomerations. Finding solutions to sustainable urban development is a global research interest, and urban metabolism is an effective approach to analysing the socio-economic system and ecosystem. In this study, three cities in the Jing-Jin-Ji urban agglomeration in China-Beijing, Tianjin and Tangshan-were selected as study cases. Multiscale integrated analysis of the societal and ecosystem metabolism (MuSIASEM) method and complete decomposition model were applied to reveal the metabolic characteristics and evolutionary trajectories of the three cities from multiple levels and dimensions. Results showed that the metabolic patterns of Beijing, Tianjin and Tangshan were service-dominated, technology and capital aggregation-dominated and traditional industry-dominated, respectively. The evolution of economic efficiency, ecological pressure and social welfare in the three cities were different because of the stage of urban development where they were located. Tianjin and Tangshan showed positive correlations between economic growth and energy consumption, whereas Beijing demonstrated a more neutral correlation. In the future, issues-such as overpopulation, labour shortage and low efficiency of energy and labour-are likely to be the key factors that impede sustainable development in the three cities, respectively. Several policy implications were raised, including the combination of population dispersal and competitive industry relocation policies for Beijing, attracting young labour in the short term and transforming the economic growth patterns in the long term for Tianjin, and industrial upgrades and technical innovation for Tangshan.
\end{abstract}

Keywords: urban metabolism; MuSIASEM; urban agglomeration; energy consumption; human activity

\section{Introduction}

Urbanisation has brought enormous prosperity to economic and cultural development since the industrial revolution. However, serious problems, such as resources depletion, environmental pollution, overpopulation, waste generation and ecological degradation have also occurred in the rapid urbanisation process. According to the United Nations Environment Programme (UNEP), urban areas account for $75 \%$ of the natural resources and $60-80 \%$ of the global GHG emissions [1]. At the same time, the proportion of the world's population living in cities is expected to increase from $54 \%$ in 2014 to $66 \%$ in 2050 [2], which will further aggravate the pressure on resources and the environment. Thus, to find solutions to these challenges and achieve sustainable development, city managers should understand the characteristics of urban metabolism. 
The concept of urban metabolism was first introduced by Wolman as an analogy to the metabolism of organisms [3]. This concept could be defined as "the sum total of the technical and socio-economic processes that occur in cities, resulting in growth, production of energy and elimination of waste" [4,5]. By evaluating and simulating the inputs, outputs and storage of elements during urban metabolic processes, urban metabolism studies could identify the causes of unhealthy urban systems (characterised by economic stagnation, overpopulation, resources depletion, environmental deterioration and social instability) and provide solutions for urban problems [6]. Currently, some common methods used in urban metabolism studies are material flow analysis $[7,8]$, energy accounting $[9,10]$ and ecological footprint analysis [11,12]. However, these methods pay insufficient attention to human activity. Moreover, the size and structure of human activity are crucial for the evolution of urban metabolism.

The multiscale integrated analysis of societal and ecosystem metabolism (MuSIASEM) method can study the sustainability of human society using heterogeneous descriptions in different domains, such as the interrelations among human activity, energy consumption and added value. In addition, this approach can reveal the metabolic characteristics across various levels and scales. The MuSIASEM approach was created by Giampietro and Mayumi [13-16] and was systematically improved later on [17-20]. Empirical analyses based on this approach varied from countries-e.g., Ecuador [21], Spain [22], China [23] and UK [24]—to regions and cities-e.g., Catalonia [25,26], Barcelona [27] and Shanghai [28])—and even to sectors [29] and households [30]. Simultaneously, several studies have focused on the comparative analysis of different metabolic patterns, including the countries of Bulgaria, Poland, Hungary and Romania [31], China and India [32], as well as 30 provinces in China [33] and Veneto and Abruzzo regions in Italy [34]. The mega-city agglomerations in China have experienced rapid urban expansion and suffered increasing urban problems in recent years, therefore the metabolic characteristics across different levels should be understood in order to diagnose their causes.

In this study, three typical cities-Beijing, Tianjin and Tangshan-in the Jing-Jin-Ji urban agglomeration in China were selected as study areas. These areas are all confronting various sustainable development challenges and following different development patterns. By using the MuSIASEM approach, this study aims to (1) provide a multiscale and multidimensional analysis of the metabolic characteristics and evolution trajectories of the three cities and then compare their differences and (2) identify the key factors that impede regional sustainability and coordinated development and then attempt to propose corresponding policy implications. The rest of this paper is organised as follows: Section 2 presents a brief introduction of the study areas, Section 3 depicts the methods and the data sources, Section 4 presents the main results under different hierarchical level analyses, Section 5 discusses the analysis results and raises corresponding policy implications, and Section 6 draws some conclusions.

\section{Study Areas}

China is a rapidly urbanising country with $54.77 \%$ of its population living in urban areas by 2014 [35]. The Jing-Jin-Ji (Beijing-Tianjin-Hebei) urban agglomeration-located in the North China Plain and bordering the Bohai Sea-is regarded as one of the key economy growth pillars of China. Beijing, Tianjin, and Tangshan (a city of Hebei province) are three of the most economically-developed cities with different characteristics in this urban agglomeration (Figure 1).

Beijing, the capital city of China, is the centre of national politics, international communication, culture and technology with a total administrative area of $16,411 \mathrm{~km}^{2}$. In 2014 , it had a population of 21.2 million, and its per capita gross domestic product (GDP) had reached 100,854 RMB (approximately US $\$ 14,646)$. Beijing can be seen as a consumer-service-driven economy because the GDP of the tertiary sector was 2.7 times higher than that of the secondary sector [36]. In the past decade, the steel sector was removed from the city and the production of high-energy-consuming industries decreased sharply. At the same time, high-end manufacturing, producer services, cultural creativity industry and tourism 
became the pillar industries of Beijing [37]. Nevertheless, the high population density and relatively high standard of living still impose enormous pressure on energy demand and the environment.

Tianjin is a municipality in China with an area of $11,917 \mathrm{~km}^{2}$ and a population of 14.7 million. It is famous for its well-established industrial foundation and rapidly developing service sector. In 2014, the per capita GDP of Tianjin was 103,684 RMB (approximately US\$15,057). The GDP size of the tertiary sector roughly equalled the secondary sector. The equipment manufacturing, petrochemical, electronic information and light and textile industries are some competitive industries of Tianjin [38]. Since Binhai New Area became a national development priority, Tianjin has experienced rapid economic growth and urbanisation, which also resulted in lots of resources and energy consumption, as well as environmental pollution.

Tangshan is a major city in Hebei Province with an area of $13,472 \mathrm{~km}^{2}$ and a population of 7.8 million. Up to 2014, the per capita GDP of Tangshan reached 80,138 RMB (approximately US $\$ 11,682)$. Tangshan represents an industry-driven economy because the GDP of the tertiary sector was only 0.6 times as high as the GDP of the secondary sector [39]. Large ecological pressure and high environmental risk ensued from this energy-driven industrial structure.

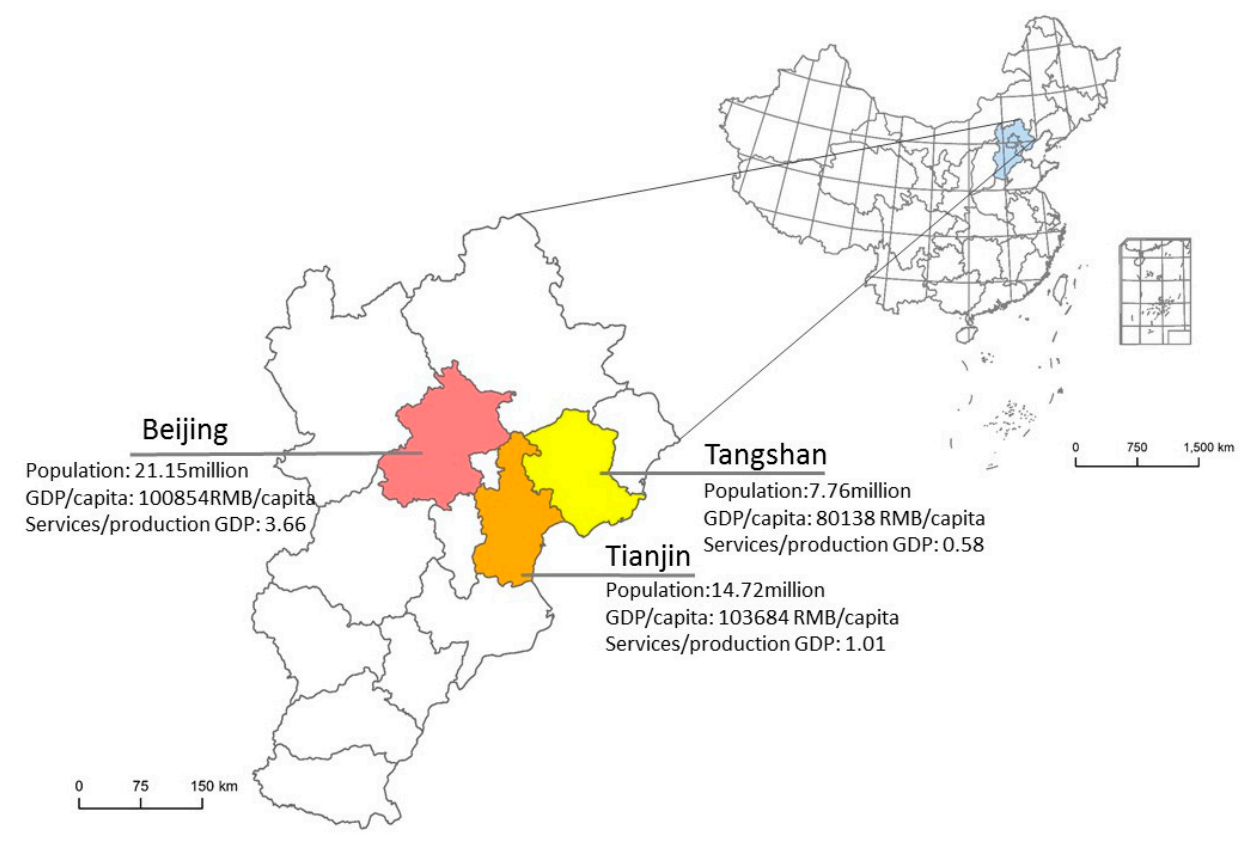

Figure 1. Location of the study areas (i.e., Beijing, Tianjin and Tangshan) in China.

\section{Methods and Data Sources}

\subsection{MUSIASEM}

\subsubsection{Methodological Framework}

The "societal and ecosystem metabolism" is a notion that urban system can be analysed based on the descriptions of energy and material transformation processes that evolve over time [40]. Figure 2 shows the schematic of urban system under this methodological framework. The two terms, namely, "endosomatic metabolism" and "exosomatic metabolism",-which originated from the double metabolism theory of Lotka [41] — should be distinguished to understand the nature of the MuSIASEM approach. Endosomatic metabolism refers to the flows of energy — called "endosomatic energy" - that are contained in food to support human physiological processes. Meanwhile, exosomatic metabolism refers to the flows of energy — called "exosomatic energy" - that are metabolised outside the human body to support production and consumption. Furthermore, the flow-fund scheme was incorporated 
into the MuSIASEM approach. Flow coordinates are elements that enter but do not exit the economic processes (e.g., energy and mineral inputs) or elements that only exit without having entered the processes (e.g., new products, added value and wastes). These coordinates are consumed or produced within economic processes. Fund coordinates are agents that enter and exit the processes (e.g., human beings, technical capital and Ricardian land), thereby transforming input flows into output flows. These coordinates are used but not consumed within economic processes and must be periodically renewed [42]. Therefore, fund coordinates entail an overhead for their maintenance and reproduction. The sustainability of economic systems depends on the steady flows under the constraints determined by the characteristics of the funds. Intrinsically, the integrated analysis of societal and ecosystem metabolism utilises a series of flow-fund, fund-fund, and flow-flow ratios to diagnose the metabolic patterns of the urban system.

The structure of an urban system can be divided into two parts in analogy to ecosystems. One is the hypercycle part, which is the net energy supplier for the rest of the systems and drives the entire system away from the thermodynamic equilibrium. The other is the dissipative part, which is the net degrader and stabilises the entire system [43]. In the natural ecosystem, autotrophs and heterotrophs belong to the hypercycle part and the dissipative part, respectively. When the ecosystem is more developed, consumers and decomposers will play a more important role in regulating the overall flows of solar energy [44]. Similarly, from the biophysical perspective, the primary sector-i.e., farming, forestry, fishery, husbandry and ranching industries-and secondary sector-i.e., mining, refining, manufacturing, energy and water supply and construction industries-are net energy and products suppliers and can be regarded as the hypercycle part. The tertiary sector-i.e., service, trade and government-and household sector-i.e., unpaid work and non-working time-are consumers of energy and products and can be considered as the dissipative part. From the economic perspective, the primary, secondary and tertiary sectors create the added value, thus these sectors are regarded as the hypercycle part. The household sector consumes the added value and thus considered as the dissipative part. If society wants to be more effective and stable, then more human activities should be allocated to the dissipative part to increase consumption and control the overproduction of the hypercycle part, thereby balancing the supply and demand [45].

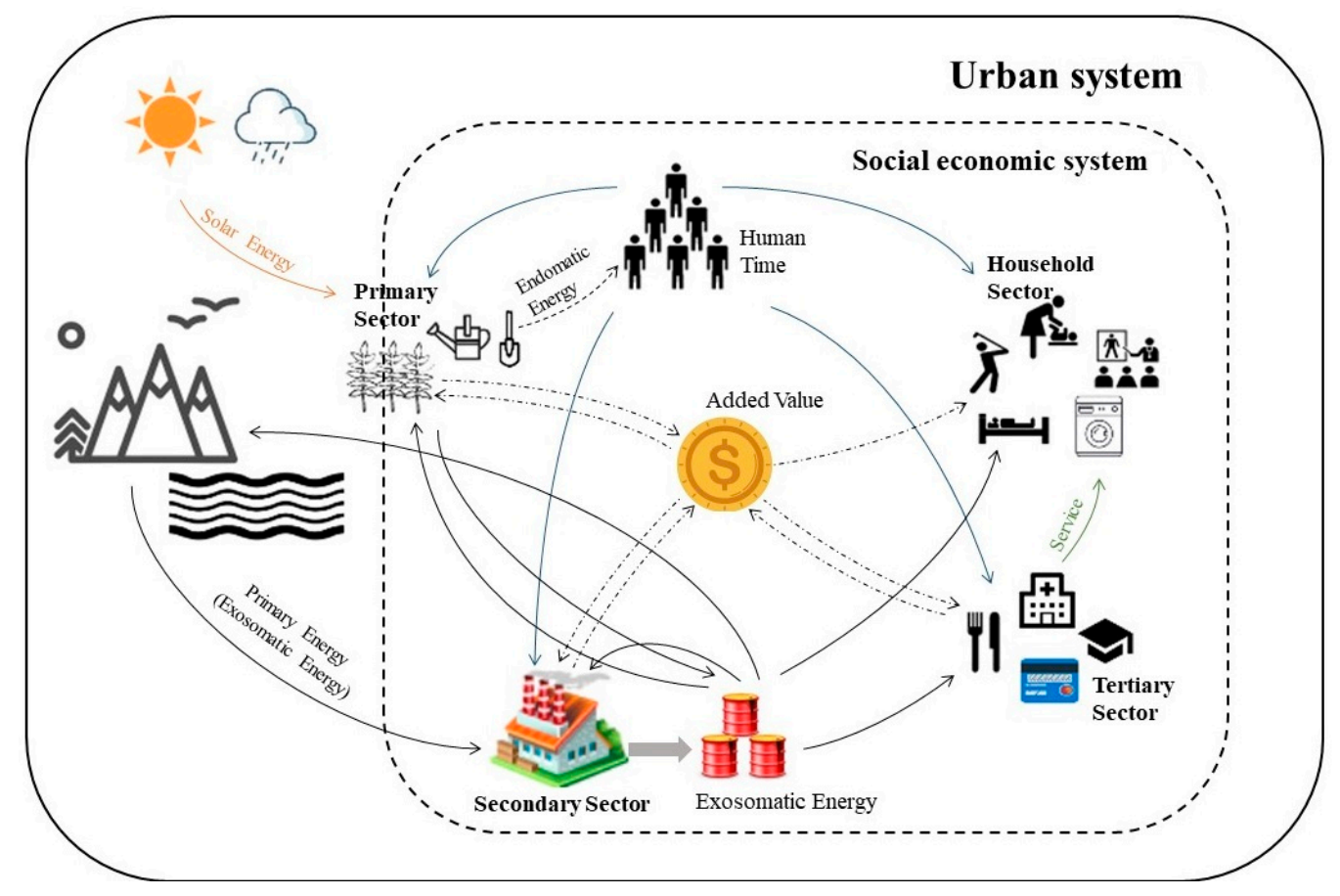

Figure 2. Schematic of the urban system under the view of societal and ecosystem metabolism. 


\subsubsection{Hierarchical Levels and Variables}

Under the MuSIASEM framework, the urban system is analysed at three hierarchical levels. Level $n$ is the entire urban system, which is divided into the paid work (PW) sector and the household $(\mathrm{HH})$ sector (level $n-1$ ). Subsequently, the PW sector is further disaggregated into three sectors (level $n-2)$, including the primary, secondary and tertiary sectors. Changes that occur at one level cannot be extrapolated to another level because of the numerous feedbacks among the sectors [22].

In this study, human activity was selected as the fund element, and energy consumption and added value were selected as the flow elements. These variables can be used at all three levels $(n, n-1$ and $n-2)$. Meanwhile, the ratios of flow-fund, fund-fund and flow-flow composed a series of variables to indicate the hierarchical structures and metabolic pattern of an urban system across different scales. All explanations of variables used in this study are as follows.

The total human activity (THA) is the total available human time for different human activities within a year, measured in hours. It is calculated by multiplying population by 8760 (365 days and $24 \mathrm{~h}$ per day) and consists of two parts, namely, human activity in the PW sector ( $\left.\mathrm{HA}_{\mathrm{PW}}\right)$ and human activity in the $\mathrm{HH}$ sector $\left(\mathrm{HA}_{\mathrm{HH}}\right)$. Human activity in the $\mathrm{PW}$ sector $\left(\mathrm{HA}_{\mathrm{PW}}\right)$ is the sum of human time allocated to the primary $\left(\mathrm{HA}_{1}\right)$, secondary $\left(\mathrm{HA}_{2}\right)$ and tertiary sectors $\left(\mathrm{HA}_{3}\right)$, whereas human activity in the $\mathrm{HH}$ sector $\left(\mathrm{HA}_{\mathrm{HH}}\right)$ is the sum of human time for unpaid work $\left(\mathrm{HA}_{\mathrm{HH}}=\mathrm{THA}-\mathrm{HA}_{\mathrm{PW}}\right)$.

The total energy throughput (TET) is the total energy consumption in the society within a year, measured in Joules. TET also consists of two parts. One is the energy throughput in the PW sector $\left(\mathrm{ET}_{\mathrm{PW}}\right)$, that is, the sum of energy consumed by the primary $\left(\mathrm{ET}_{1}\right)$, secondary $\left(\mathrm{ET}_{2}\right)$ and tertiary sectors $\left(\mathrm{ET}_{3}\right)$; and the other is the energy throughput in the $\mathrm{HH}$ sector $\left(\mathrm{ET}_{\mathrm{HH}}\right)$.

GDP is an added value generated by the society within a year, measured in 2000 constant dollars. It is the sum of the added value generated by the primary $\left(\mathrm{GDP}_{1}\right)$, secondary $\left(\mathrm{GDP}_{2}\right)$ and tertiary sectors $\left(\mathrm{GDP}_{3}\right)$.

Energy intensity (EI) is the energy efficiency with respect to the added value. The EI of societal average $\left(\mathrm{EI}_{\mathrm{SA}}\right)$ is the total energy consumption (TET) per unit of GDP, whereas the EI of sector $\mathrm{i}\left(\mathrm{EI}_{\mathrm{i}}\right)$ is the energy consumption in sector $\mathrm{i}\left(\mathrm{ET}_{\mathrm{i}}\right)$ per unit of added value in sector $\mathrm{i}\left(\mathrm{GDP}_{\mathrm{i}}\right)$.

Economic labour productivity (ELP) reflects the economic efficiency of the PW sector in producing goods and services. ELP of the PW sector $\left(\right.$ ELP $\left._{\mathrm{PW}}\right)$ is the GDP per hour of human activity in the PW sector $\left(\mathrm{HA}_{\mathrm{PW}}\right)$, whereas the ELP of sector $\mathrm{i}\left(\mathrm{ELP}_{\mathrm{i}}\right)$ is the added value in sector $\mathrm{i}\left(\mathrm{GDP}_{\mathrm{i}}\right)$ per hour of human activity in sector $\mathrm{i}\left(\mathrm{HA}_{\mathrm{i}}\right)$.

The exosomatic metabolic rate (EMR) of the societal average $\left(E R_{S A}\right)$ is the total energy consumption (TET) per hour of human time available to society (THA), whereas the EMR of sector $\mathrm{i}\left(\mathrm{EMR}_{\mathrm{i}}\right)$ is the energy consumption in sector $\mathrm{i}\left(\mathrm{ET}_{\mathrm{i}}\right)$ per hour of human activity in sector $\mathrm{i}\left(\mathrm{HA}_{\mathrm{i}}\right)$. For the $\mathrm{HH}$ sector, the $\mathrm{EMR}_{\mathrm{HH}}$ reflects the material standard of living, such as the use of household appliances [16]. For the PW sector, the EMR $\mathrm{PW}_{\mathrm{PW}}$ and the EMR of primary, secondary and tertiary sectors reflect the use of technologies-i.e., using more technologies indicates more energy throughput and less human activity allocated to the PW sector-and the level of capitalisation-i.e., more investment in machinery and tools for the production of goods and services indicates more energy throughput

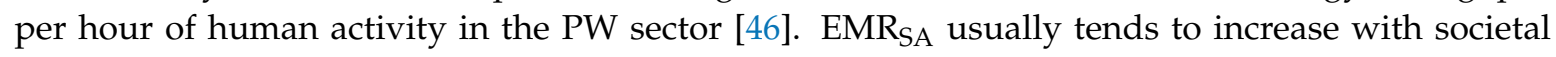
development but is still influenced by the changes of sector structure.

The societal overhead of human activity (SOHA) is expressed by the ratio of $\mathrm{HA}_{\mathrm{HH}}$ and $\mathrm{HA}_{\mathrm{PW}}$. That is, to have effective economic activities, certain time has to be allocated to support social welfare. A higher SOHA value represents better human well-being because people have more time for education, leisure and other unpaid activities; however, it also represents higher pressure of support because of the increase in human activity in the $\mathrm{HH}$ sector $\left(\mathrm{HA}_{\mathrm{HH}}\right)$ supported by each hour of human activity in PW sector $\left(\mathrm{HA}_{\mathrm{PW}}\right)$. Additionally, human activity would be periodically renewed because of the characteristics of fund element. The change of SOHA is the key factor to determine whether the current economic growth patterns will be sustainable in the long term. 
Biological-economic pressure (BEP) indicates the ecological pressure with social development and equals the TET divided by the hours of human activity in the primary and secondary sectors $\left(\mathrm{HA}_{1}+\mathrm{HA}_{2}\right)$. BEP reflects the amount of energy that should be supplied by hourly human activity in the production sector, given the current energy consumption patterns [16]. If the BEP of one region is high, then it might exceed the upper limit of energy production per hour of human activity in the production sector. Thus, people will have to overexploit local resources and import energy from outside producers, which will increase the pressure on the environment locally and regionally.

Table 1 lists all variables with their calculation formulas and abbreviations.

Table 1. Variables used in the Multi-Scale Integrated Analysis of Societal and Ecosystem Metabolism (MuSIASEM) approach.

\begin{tabular}{|c|c|c|c|c|}
\hline Variables & Abbreviation & Nature & Calculation Formulas & Unit \\
\hline Total human activity & THA & Fund & $\begin{array}{c}\text { THA }=\text { Population } \times 8760 \\
(365 \text { days and } 24 \text { h per day) }\end{array}$ & $\mathrm{h}$ \\
\hline Human activity in sector i & $\mathrm{HA}_{\mathrm{i}}$ & Fund & $\begin{array}{c}\mathrm{HA}_{\mathrm{PW}}=\mathrm{HA}_{1}+\mathrm{HA}_{2}+\mathrm{HA}_{3} \\
\mathrm{HA}_{\mathrm{HH}}=\mathrm{THA}-\mathrm{HA}_{\mathrm{PW}}\end{array}$ & $\mathrm{h}$ \\
\hline Total energy throughput & TET & Flow & $\mathrm{TET}=\mathrm{ET}_{\mathrm{PW}}+\mathrm{ET}_{\mathrm{HH}}$ & PJ \\
\hline $\begin{array}{l}\text { Energy throughput in } \\
\text { sector } \mathrm{i}\end{array}$ & $\mathrm{ET}_{\mathrm{i}}$ & Flow & $\mathrm{ET}_{\mathrm{PW}}=\mathrm{ET}_{1}+\mathrm{ET}_{2}+\mathrm{ET}_{3}$ & PJ \\
\hline Gross domestic product & GDP & Flow & - & US\$ \\
\hline Added value in sector $\mathrm{i}$ & $\mathrm{GDP}_{\mathrm{i}}$ & Flow & - & US\$ \\
\hline $\begin{array}{l}\text { Energy intensity of societal } \\
\text { average/sector i }\end{array}$ & $\mathrm{EI}_{\mathrm{SA}} / \mathrm{EI}_{\mathrm{i}}$ & Flow-flow ratio & $\begin{array}{c}\mathrm{EI}_{\mathrm{SA}}=\mathrm{TET} / \mathrm{GDP} \\
\mathrm{EI}_{\mathrm{i}}=\mathrm{ET}_{\mathrm{i}} / \mathrm{GDP}_{\mathrm{i}}\end{array}$ & MJ/US\$ \\
\hline $\begin{array}{c}\text { Economic labour } \\
\text { productivity of sector i }\end{array}$ & $E L P_{i}$ & Flow-fund ratio & $\begin{aligned} \mathrm{ELP}_{\mathrm{PW}} & =\mathrm{GDP} / \mathrm{HA}_{\mathrm{PW}} \\
\mathrm{ELP}_{\mathrm{i}} & =\mathrm{GDP}_{\mathrm{i}} / \mathrm{HA}_{\mathrm{i}}\end{aligned}$ & $\mathrm{US} \$ / \mathrm{h}$ \\
\hline $\begin{array}{l}\text { Exosomatic metabolic rate } \\
\text { of societal average/sector i }\end{array}$ & $\mathrm{EMR}_{\mathrm{SA}} / \mathrm{EMR}_{\mathrm{i}}$ & Flow-fund ratio & $\begin{aligned} \mathrm{EMR}_{\mathrm{SA}} & =\mathrm{TET} / \mathrm{THA} \\
\mathrm{EMR}_{\mathrm{i}} & =\mathrm{ET}_{\mathrm{i}} / \mathrm{HA}_{\mathrm{i}}\end{aligned}$ & $\mathrm{MJ} / \mathrm{h}$ \\
\hline $\begin{array}{l}\text { Societal overhead of } \\
\text { human activity }\end{array}$ & SOHA & Fund-fund ratio & $\mathrm{SOHA}=\mathrm{HA}_{\mathrm{HH}} / \mathrm{HA}_{\mathrm{PW}}$ & $\mathrm{h} / \mathrm{h}$ \\
\hline $\begin{array}{l}\text { Biological-economic } \\
\text { pressure }\end{array}$ & $\mathrm{BEP}$ & Flow-fund ratio & $\mathrm{BEP}=\mathrm{TET} /\left(\mathrm{HA}_{1}+\mathrm{HA}_{2}\right)$ & $\mathrm{MJ} / \mathrm{h}$ \\
\hline
\end{tabular}

\subsubsection{Sustainable Urban Development and the MuSIASEM Framework}

"Sustainable development" was brought into common use by the Brundtland Commission in 1987, which called for "meeting the needs of the present generation without compromising the needs of future generations" [47]. Since then, a great deal of research has been conducted to discuss the operational concept of sustainable development.

The urban system is a complex system of nature-economy-society. Sustainable urban development implies the collaborative evolution of society, economy and ecology to promote social welfare, economic growth and efficiency, ecological balance and reduction of energy use [48,49]. According to Niu [50], sustainable urban development reveals the systematic essence of "development, coordination and sustainability." Development focuses on productivity improvement and social progress, including the capability, potential and speed of development. Coordination focuses on internal efficiency, such as the material standard of living and energy efficiency. Sustainability determines the long-term reasonability of development progress. As previously mentioned, the MuSIASEM framework, which uses the different descriptions in domains of society, economy and ecology, is an effective tool to measure the sustainable urban development from different dimensions (Table 2). 
Table 2. MuSIASEM variables for measuring sustainable urban development.

\begin{tabular}{|c|c|c|c|c|c|c|c|c|}
\hline $\begin{array}{ll}\text { Dimesions } & \text { Variables } \\
\end{array}$ & THA$/ \mathbf{H A}_{\mathbf{i}}$ & $\mathrm{TET} \mathrm{ET}_{\mathrm{i}}$ & GDP/GD & $\mathbf{E I}_{\mathbf{i}}$ & $\mathbf{E L P}_{\mathrm{i}}$ & $\mathrm{EMR}_{\mathbf{i}}$ & SOHA & BEP \\
\hline Development & $\sqrt{ }$ & & $\sqrt{ }$ & & & & & \\
\hline Coordination & & & & $\sqrt{ }$ & $\sqrt{ }$ & $\sqrt{ }$ & & \\
\hline Sustainability & & $\sqrt{ }$ & & & & & $\sqrt{ }$ & $\sqrt{ }$ \\
\hline
\end{tabular}

\subsection{Complete Decomposition Model}

A complete decomposition model is applied to identify the key factors that influence the changes of EMR, namely, technology and capital aggregation and sector structure [51]. Consequently, $\mathrm{r}_{\text {aggregate }}$ and $r_{\text {structure }}$ are two indicators that represent the contribution of technology and capital aggregation and sector structure, respectively. Their positive or negative signs indicate the positive or negative effects of the factors, respectively. The specific decomposition steps are as follows:

$$
E M R=\frac{T E T}{T H A}=\sum_{i=1}^{n} E T_{i} / T H A=\sum_{i=1}^{n}\left(\frac{E T_{i}}{H A_{i}} \times \frac{H A_{i}}{T H A}\right)=\sum_{i=1}^{n}\left(E M R_{i} \times S_{i}\right)(n=1,2, \ldots, n),
$$

where $E T_{i}$ is the energy throughput in sector $i, H A_{i}$ is the amount of human time invested in sector $i$, $E M R_{i}$ is the EMR in sector $i$ and $S_{i}$ is the rate of human time used in sector $i$ to the total human time. The changes of EMR can be further decomposed as:

$$
\begin{aligned}
& \Delta E M R=E M R^{t}-E M R^{0}=\sum_{i=1}^{n}\left(E M R_{i}^{t} \times S_{i}^{t}\right)-\sum_{i=1}^{n}\left(E M R_{i}^{0}-S_{i}^{0}\right) \\
& =\sum_{i=1}^{n}\left(E M R_{i}^{t}-E M R_{i}^{0}\right) \times S_{i}^{0}+\sum_{i=1}^{n}\left(S_{i}^{t}-S_{i}^{0}\right) \times E M R_{i}^{0}+\sum_{i=1}^{n}\left(E M R_{i}^{t}-E M R_{i}^{0}\right) \times\left(S_{i}^{t}-S_{i}^{0}\right) \\
& =\sum_{i=1}^{n} \Delta E M R_{i} \times S_{i}^{0}+\sum_{i=1}^{n} \Delta S_{i} \times E M R_{i}^{0}+\sum_{i=1}^{n} \Delta E M R_{i} \times \Delta S_{i}
\end{aligned}
$$

where $\triangle E M R$ and $\triangle E M R_{i}$ are the changes of the exosomatic metabolic rate in the entire system and sector $i$ from the baseline year to year $t$, respectively; $E M R^{t}$ and $E M R^{0}$ are the exosomatic metabolic rates of the entire system in the baseline year and in year $t$, respectively, $E M R_{i}^{t}$ and $E M R_{i}^{0}$ are the exosomatic metabolic rates in the sector $i$ in the baseline year and in year $t$, respectively; $S_{i}^{t}$ and $S_{i}^{0}$ are the rates of human time used in sector $i$ to the total human time in the baseline year and in year $t$, respectively; and $\Delta S_{i}$ is the rate changes of human time used in sector $i$ to the total human time from baseline year to year $t$.

The changes of EMR can be decomposed into two parts, namely, $E M R_{\text {aggregate }}$ and $E M R_{\text {structure, }}$ as expressed as follows:

$$
\begin{aligned}
& E M R_{\text {aggregate }}=\sum_{i=1}^{n} \Delta E M R_{i} \times S_{i}^{0}+\frac{1}{2} \sum_{i=1}^{n} \Delta E M R_{i} \times \Delta S_{i}, \\
& E M R_{\text {structure }}=\sum_{i=1}^{n} \Delta S_{i} \times E M R_{i}^{0}+\frac{1}{2} \sum_{i=1}^{n} \Delta E M R_{i} \times \Delta S_{i} .
\end{aligned}
$$

The contribution rate of technology and capital aggregation $\left(r_{\text {aggregate }}\right)$ and the contribution rate of the sector structure $\left(r_{\text {structure }}\right)$ to the changes of EMR can be expressed as

$$
\begin{aligned}
& r_{\text {aggregate }}=\frac{E M R_{\text {aggregate }}}{\Delta E M R} \times 100 \%, \\
& r_{\text {structure }}=\frac{E M R_{\text {structure }}}{\Delta E M R} \times 100 \% .
\end{aligned}
$$




\subsection{Data Sources}

Data on THA were obtained from the population data in the statistical yearbooks of Beijing, Tianjin, and Tangshan. The population data were multiplied by $8760 \mathrm{~h} /$ year to calculate the THA per year expressed in hours, using the convention of 365 days and 24 hours per day. The hours of human activity in the $\mathrm{PW}$ sector $\left(\mathrm{HA}_{\mathrm{PW}}\right)$ were obtained from the number of employment and working hours per week by sector of economic activity, assuming 50 work weeks per year. Data that concern the employment by sector of economic activity were obtained from Beijing, Tianjin, and Tangshan statistical yearbooks, and the working hours per week by sector of economic activity were obtained from the China labour statistical yearbook (National-level data were used as replacements because the data on weekly working hours by sector were not available at city levels). The hours of human activity in the $\mathrm{HH}$ sector $\left(\mathrm{HA}_{\mathrm{HH}}\right)$ were calculated by $\mathrm{HA}_{\mathrm{HH}}=\mathrm{THA}-\mathrm{HA}$ PW

The data on total energy consumption and by sector were obtained from the Energy Balances of Beijing, Tianjin and Tangshan statistical yearbooks. Energy loss during the processes of energy conversion was distributed to the secondary sector. Energy loss during the courses of energy transport, distribution and storage was distributed to the transportation sector, which belongs to the tertiary sector. The energy consumption of the HH sector includes energy consumption for cooking, lighting, heating and cooling, recreation and private transportation.

GDP and GDP by sector statistics were obtained from Beijing, Tianjin, and Tangshan statistical yearbooks and were converted into constant 2000 dollars.

The analysis period was from 2005 to 2014 . The aforementioned statistical data were all provided by the National Bureau of Statistics of China and Regional Bureau of Statistics. Although some suspicions about the reliability of the Chinese official data were observed, the official data with their credibility and effectiveness were still widely used in academic studies and policymaking at the city level.

\section{Results}

\subsection{Level n: City Level}

Over the study period (2005-2014), GDP continuously increased at an annual average rate of $8.9 \%$, $13.0 \%$ and $10.5 \%$ in Beijing, Tianjin, and Tangshan, respectively. THA increased more slowly than GDP. For Beijing and Tianjin, the annual growth rate of THA was approximately $3.5 \%$, whereas it was only $0.6 \%$ for Tangshan (Table 3). As for energy consumption, TET increased with the development of the economy, especially for Tianjin and Tangshan (Figure 3). However, a downward trend was observed in the energy intensity of the societal average $\left(\mathrm{EI}_{\mathrm{SA}}\right)$, which indicated the improvements of energy efficiency at the city level.

Table 3. Main data at the city level used in MuSIASEM analysis.

\begin{tabular}{|c|c|c|c|c|c|c|c|c|c|}
\hline \multirow[b]{2}{*}{ Year } & \multicolumn{3}{|c|}{ Beijing } & \multicolumn{3}{|c|}{ Tianjin } & \multicolumn{3}{|c|}{ Tangshan } \\
\hline & $\begin{array}{c}\text { GDP } \\
\text { (Billion US\$) }\end{array}$ & $\begin{array}{c}\text { THA } \\
\text { (Billion h) }\end{array}$ & $\begin{array}{l}\text { TET } \\
\text { (PJ) }\end{array}$ & $\begin{array}{c}\text { GDP } \\
\text { (Billion US\$) }\end{array}$ & $\begin{array}{c}\text { THA } \\
\text { (Billion h) }\end{array}$ & $\begin{array}{l}\text { TET } \\
(\mathrm{PJ})\end{array}$ & $\begin{array}{c}\text { GDP } \\
\text { (Billion US\$) }\end{array}$ & $\begin{array}{c}\text { THA } \\
\text { (Billion h) }\end{array}$ & $\begin{array}{l}\text { TET } \\
(\mathrm{PJ})\end{array}$ \\
\hline 2005 & 67.5 & 134.7 & 1616.3 & 39.6 & 91.4 & 1204.6 & 20.1 & 63.6 & 1748.5 \\
\hline 2006 & 76.3 & 140.2 & 1728.2 & 45.5 & 94.2 & 1324.6 & 23.0 & 64.2 & 1946.3 \\
\hline 2007 & 87.4 & 146.8 & 1839.7 & 52.5 & 97.7 & 1447.3 & 26.5 & 64.7 & 2149.1 \\
\hline 2008 & 95.4 & 155.1 & 1852.0 & 61.2 & 103.0 & 1570.0 & 29.9 & 65.1 & 2276.0 \\
\hline 2009 & 105.1 & 162.9 & 1923.2 & 71.3 & 107.6 & 1719.4 & 33.3 & 65.4 & 2402.2 \\
\hline 2010 & 116.0 & 171.9 & 2034.3 & 83.7 & 113.8 & 1995.7 & 37.7 & 66.4 & 2612.8 \\
\hline 2011 & 125.4 & 176.8 & 2044.5 & 97.4 & 118.7 & 2224.1 & 42.1 & 66.8 & 2796.2 \\
\hline 2012 & 135.0 & 181.3 & 2098.7 & 110.9 & 123.8 & 2402.6 & 46.5 & 67.2 & 2866.8 \\
\hline 2013 & 145.4 & 185.3 & 1968.1 & 124.7 & 129.0 & 2582.6 & 50.3 & 67.5 & 2970.4 \\
\hline 2014 & 156.0 & 188.5 & 1999.6 & 137.2 & 132.9 & 2384.1 & 52.9 & 68.0 & 2375.0 \\
\hline $\begin{array}{l}\text { Annual } \\
\text { growth rate }\end{array}$ & $8.9 \%$ & $3.6 \%$ & $3.0 \%$ & $13.0 \%$ & $3.5 \%$ & $8.0 \%$ & $10.5 \%$ & $0.6 \%$ & $5.8 \%$ \\
\hline
\end{tabular}


The level of $\mathrm{EI}_{\mathrm{SA}}$ varied in the three cities (Figure 3). Beijing showed the lowest $\mathrm{EI}_{\mathrm{SA}}$ or the highest energy efficiency. The $\mathrm{EI}_{\mathrm{SA}}$ of Tianjin was slightly higher than that of Beijing, whereas that of Tangshan was almost 2.8 times higher than that of Beijing. The exosomatic metabolic rates of societal average $\left(\mathrm{EMR}_{\mathrm{SA}}\right)$ were also highly varied in the three cities (Figure 4). For Tianjin and Tangshan, the EMRSA went from 13.2 MJ/h and 27.5 MJ/h in 2005 to $17.9 \mathrm{MJ} / \mathrm{h}$ and $34.9 \mathrm{MJ} / \mathrm{h}$ in 2014, respectively. The upward trend reflected the increase in the level of technologies and capitalisation or the improvements of standard of living in Tianjin and Tangshan (except for 2014 because many enterprises closed in response to steel overcapacity and air pollution). For Beijing, the EMR $\mathrm{SA}_{\mathrm{SA}}$ decreased from $12.0 \mathrm{MJ} / \mathrm{h}$ in 2005 to $10.6 \mathrm{MJ} / \mathrm{h}$ in 2014 . Given the economic prosperity of Beijing in the last decade, the downward trend seemed to be "abnormal." This behaviour was probably due to the changes of the structural composition of the economy in Beijing, and specific reasons could be further explored at the lower level.
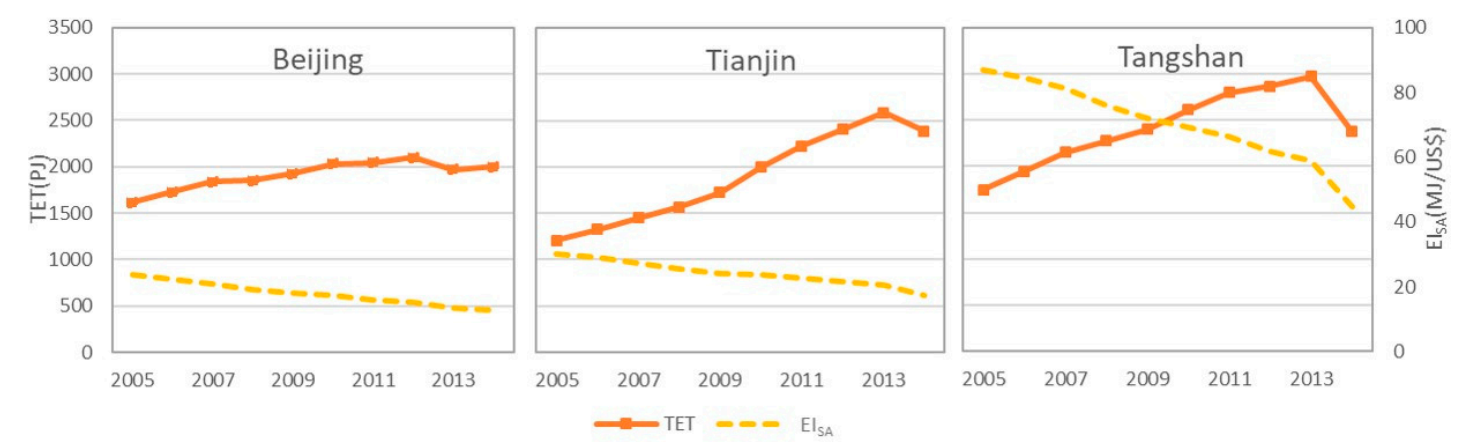

Figure 3. TET and EISA of Beijing, Tianjin, and Tangshan from 2005 to 2014.

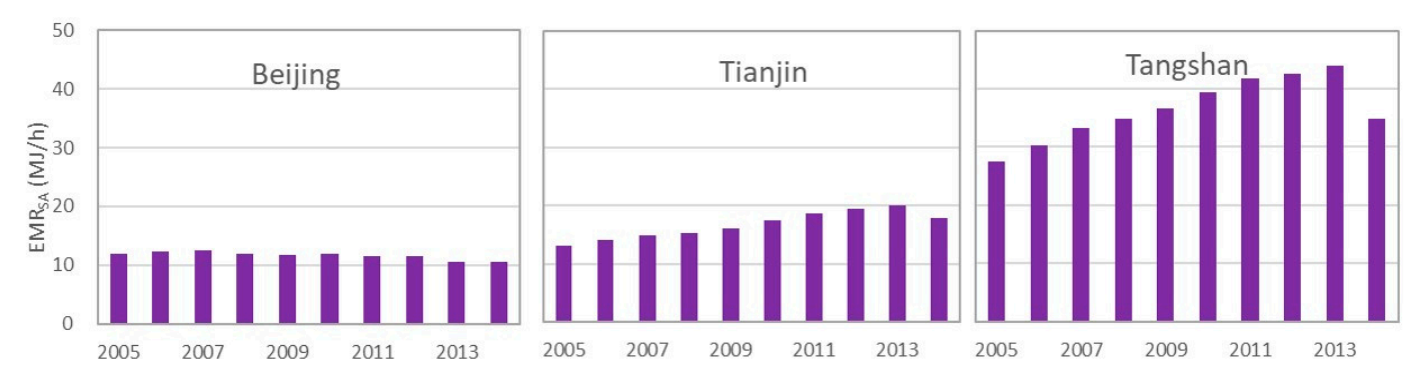

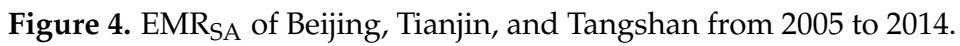

\subsection{Level $n-1$ : Production and Consumption}

To explain the changes of EMR $\mathrm{SA}_{\mathrm{A}}$ in the analysis period, the data were divided into production side (PW sector) and consumption side (HH sector). At level $n-1$, the changes in the metabolic rates and distribution of human activity could be checked.

In Beijing, the EMR $\mathrm{PW}_{\mathrm{PW}}$ decreased from $66.4 \mathrm{MJ} / \mathrm{h}$ in 2005 to $58.3 \mathrm{MJ} / \mathrm{h}$ in 2014 because the growth rate of energy throughput was lower than that of human activity in the PW sector. This finding indicates that the increase in $\mathrm{ET}_{\mathrm{PW}}$ from 1378.0 PJ in 2005 to $1559.2 \mathrm{PJ}$ in 2014 did not contribute to the use of technologies and the level of capitalisation but it only provided the new work force with even less energy for work. In Tianjin, the $\mathrm{EMR}_{\mathrm{PW}}$ experienced a stable growth with an annual growth rate of $4.1 \%$ in $\mathrm{HA}_{\mathrm{PW}}$ and $8.15 \%$ in $\mathrm{ET}_{\mathrm{PW}}$. In Tangshan, the growth rate of $\mathrm{HA}_{\mathrm{PW}}$ was extremely low $(0.1 \%$ per year), whereas the growth rate of $\mathrm{ET}_{\mathrm{PW}}$ was relatively high (6.0\% per year). Accordingly, the $\mathrm{EMR}_{\mathrm{PW}}$ increased more rapidly than that of Tianjin, except in 2014, due to the policies of capacity compression and air pollution control (Figure 5a). The increase in EMR $\mathrm{PW}_{\mathrm{W}}$ in Tianjin and Tangshan implied the agglomeration of technology and capital, which corresponded to their economic development during the analysis period. 
Figure $5 b$ shows that Beijing had the highest as well as increasing $\mathrm{EMR}_{\mathrm{HH}}$, which indicated the highest and improving material standard of living of the city. Tianjin also showed a similar trend to that of Beijing but with some fluctuations. The EMR $\mathrm{HH}_{\mathrm{H}}$ of Tangshan was similar to that of Tianjin before 2011 but decreased to the lowest in 2012 and during the next two years, which may be due to the heating systems of Tangshan being technically upgraded to save more energy over these years.

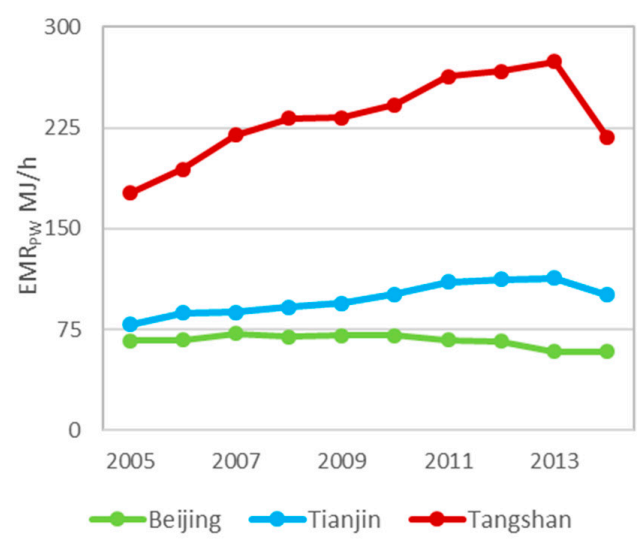

(a)

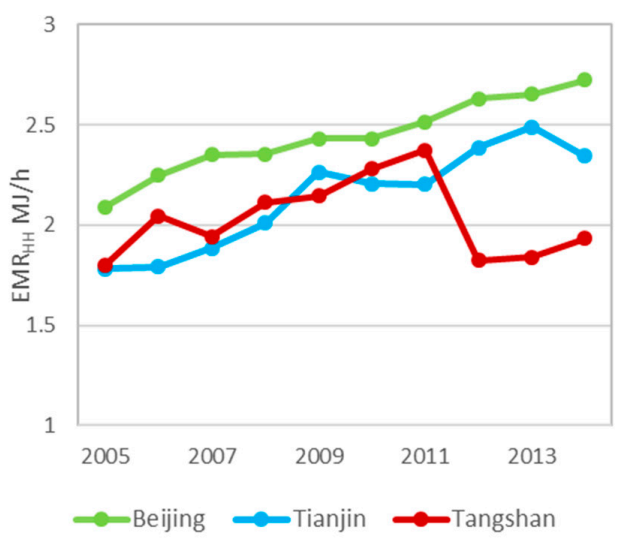

(b)

Figure 5. EMR $\mathrm{PW}_{\mathrm{P}}(\mathbf{a})$ and $\mathrm{EMR}_{\mathrm{HH}}(\mathbf{b})$ of Beijing, Tianjin and Tangshan from 2005 to 2014.

The results of the complete decomposition model identified the contribution of technology and capital aggregation and sector structure to the changes of EMR

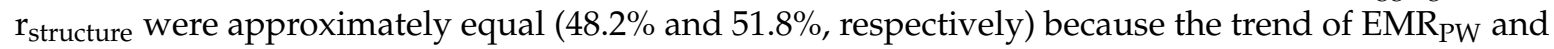
the percentage of human activity allocated to the PW sector both decreased. For Tianjin and Tangshan, the $r_{\text {structure }}$ and $r_{\text {aggregate }}$ were $19.8 \%$ and $80.2 \%$, and $14.8 \%$ and $85.2 \%$, respectively, due to the stable distribution of human activity and the increase in $\mathrm{EMR}_{\mathrm{PW}}$ in the two cities.

In addition, the relationships between $\mathrm{EMR}_{\mathrm{PW}}$ and $\mathrm{ELP}_{\mathrm{PW}}$ in the three cities varied (Figure 6). Generally, a positive correlation between $\mathrm{EMR}_{\mathrm{PW}}$ and $\mathrm{ELP}_{\mathrm{PW}}$ exists because of the following two perspectives: higher $\mathrm{EMR}_{\mathrm{PW}}$ indicates an increased use of machinery and tools for production of goods and services, thereby promoting a greater $\mathrm{ELP}_{\mathrm{PW}}$ [25]; and higher $\mathrm{EMR}_{\mathrm{PW}}$ indicates greater capitalisation of production, implying larger costs that will not be covered unless this change allows greater $\mathrm{ELP}_{\mathrm{PW}}$ [32]. However, the $\mathrm{ELP}_{\mathrm{PW}}$ of Beijing significantly increased with a decreasing $\mathrm{EMR}_{\mathrm{PW}}$. Tangshan had the lowest ELP $_{\mathrm{PW}}$ but the highest $\mathrm{EMR}_{\mathrm{PW}}$ among all the three cities. Their different behaviours were also due to the structural composition of the economy. Beijing experienced a structural change that reduced human activity in the secondary sector with higher EMR and increased human activity in the service sector with lower EMR but higher ELP, whereas Tangshan depended more on the secondary sector characterised by higher EMR. More analysis needs to be conducted to explore the reasons at level $n-2$.
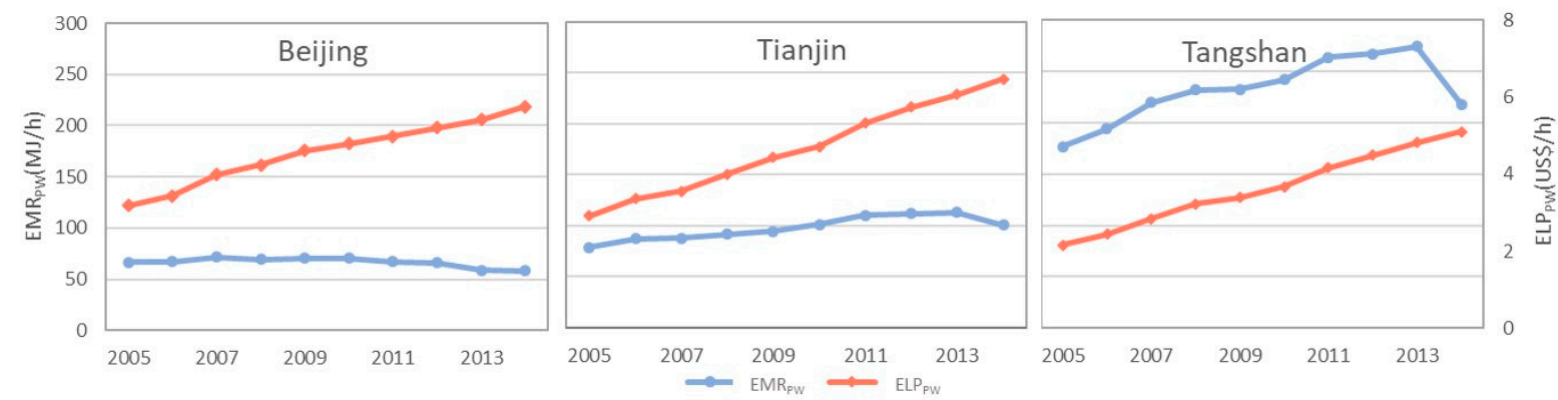

Figure 6. EMR $\mathrm{PW}_{\mathrm{P}}$ and $\mathrm{ELP}_{\mathrm{PW}}$ of Beijing, Tianjin and Tangshan from 2005 to 2014. 


\subsection{Level $n-2$ : Primary, Secondary and Tertiary Sectors}

Figure 7 demonstrates the metabolic patterns of primary, secondary and tertiary sectors of Beijing, Tianjin, and Tangshan from 2005 to 2014. The horizontal and vertical axes represent the ELP and EMR of the three sectors, respectively. The size of each bubble represents the annual hours of human activity in each sector. The different metabolic characteristics of the three sectors are clearly observed-primary sector with the lowest ELP and EMR and secondary sector with the highest ELP and EMR. Figure 8 and Table 4 present the EI of the three sectors and some sub-sectors of the industries in Beijing, Tianjin, and Tangshan. Consequently, the different structures and compositions of the three sectors caused the different metabolic characteristics of the PW sector.
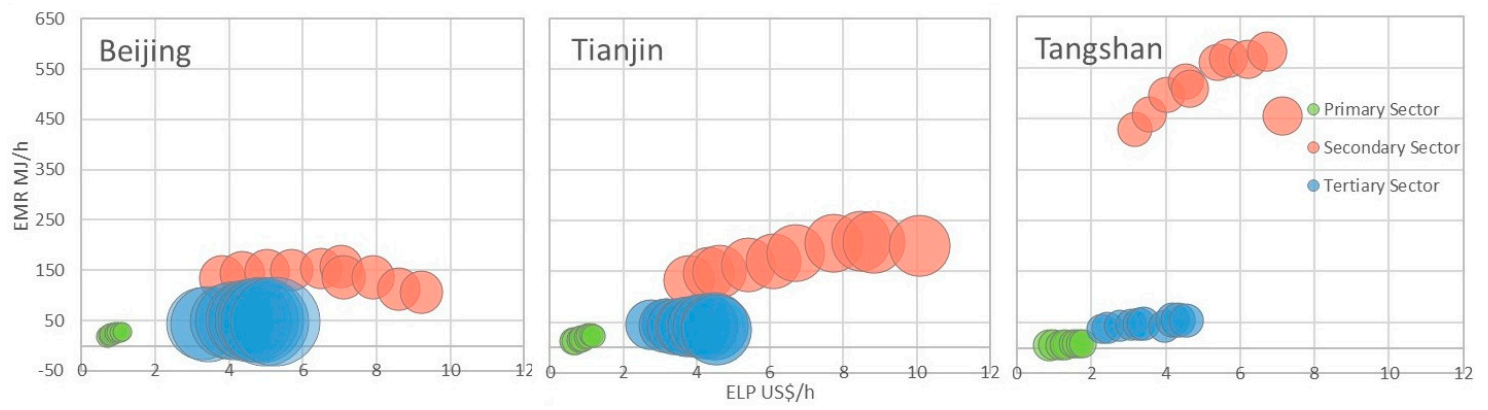

Figure 7. Metabolic pattern of the three sectors of Beijing, Tianjin, and Tangshan from 2005 to 2014.

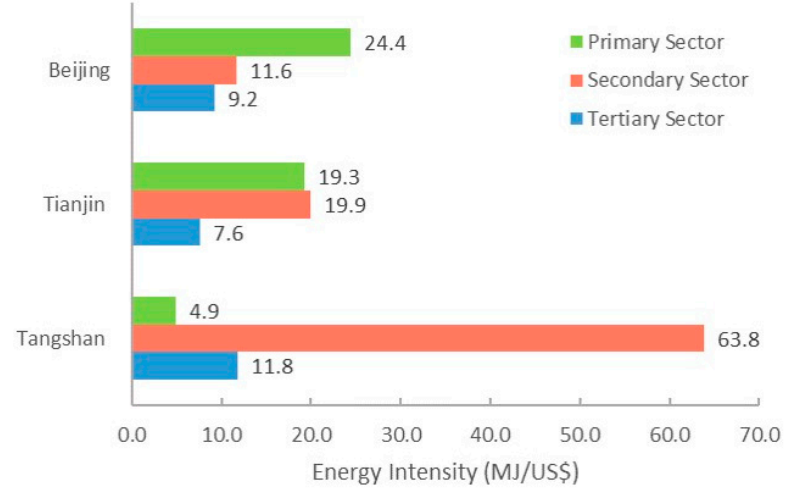

Figure 8. Energy Intensity (EI) of the three sectors in Beijing, Tianjin, and Tangshan in 2014.

In Beijing, the primary and secondary sectors lost $2.8 \%$ and $8.8 \%$ in human activity from 2005 to 2014, respectively, which implied that a fraction of the work force moved to the tertiary sector (a non-energy-intensive sector). At the same time, the $\mathrm{EMR}_{2}$ decreased based on the development of high-end manufacturing (e.g., the last four sub-sectors shown in Table 4) and the relocation of the steel sector (e.g., the manufacturing and pressing of ferrous metals). The two reasons above might explain the decreasing trend of $\mathrm{EMR}_{\mathrm{PW}}$ in Beijing. The ELP of the three sectors continuously increased, causing the ELP $P_{\mathrm{PW}}$ of Beijing to increase in these years.

The primary and secondary sectors in Tianjin also lost $7.1 \%$ and $3.4 \%$ of human activity during the analysis period, respectively. These active work forces moved to the tertiary sector. However, the size and proportion of human activity allocated to the secondary sector in Tianjin were considerably greater than those in Beijing, and the $\mathrm{EMR}_{2}$ also increased in these years. These two conditions might explain the stable increase in EMR $\mathrm{PW}_{\mathrm{P}}$ in Tianjin. The ELP of the three sectors also continued to increase, which caused a significant increase in the ELP $\mathrm{PW}_{\mathrm{W}}$ of Tianjin.

In Tangshan, a total of $10.7 \%$ of human activity moved from the primary sector to the secondary and tertiary sectors in the analysis period. By contrast, the $\mathrm{EMR}_{2}$ of Tangshan was 3.3 times higher than that of Beijing and 1.3 times higher than that of Tianjin. Nevertheless, the ELP 2 of Tangshan was 
lower than that of Beijing and Tianjin due to the low energy efficiency of its leading industries (e.g., the first four sub-sectors shown in Table 4). The same pattern was also observed for the tertiary sector of Tangshan. As a result, the higher level of $\mathrm{EMR}_{\mathrm{PW}}$ did not bring the higher level of ELPPW, namely, higher economic efficiency.

Table 4. EI of some sub-sectors of industry in Beijing, Tianjin and Tangshan in 2014.

\begin{tabular}{|c|c|c|c|}
\hline \multirow{2}{*}{ Sub-Sectors of Industry Sector } & \multicolumn{3}{|c|}{ Energy Intensity (MJ/US\$) } \\
\hline & Beijing & Tianjin & Tangshan \\
\hline Processing of petroleum, coking and nuclear fuel & 126.1 & 108.1 & 105.0 \\
\hline Manufacture of raw chemical materials and products & 62.7 & 94.6 & 159.2 \\
\hline Manufacture of non-metallic mineral products & 89.7 & 48.7 & 80.5 \\
\hline Manufacture and pressing of ferrous metals & 96.9 & 103.9 & 144.6 \\
\hline Manufacture of medicines & 4.6 & 2.1 & 17.9 \\
\hline Manufacture of motor vehicles & 5.7 & 4.6 & 7.7 \\
\hline Manufacture of railway, watercraft, aerospace and other transport equipment & 7.1 & 5.4 & 7.5 \\
\hline Computer, communication equipment and other electronic equipment & 11.3 & 3.7 & 8.3 \\
\hline
\end{tabular}

Figure 9 presents the contribution rates of technology and capital aggregation $\left(\mathrm{r}_{\text {aggregate }}\right)$ and sector structure $\left(\mathrm{r}_{\text {structure }}\right)$ to the changes of $\mathrm{EMR}_{\mathrm{PW}}$ by using a complete decomposition model. For Beijing, the sector structure and aggregation factors accounted for the decrease of $\mathrm{EMR}_{\mathrm{PW}}$ by $73.3 \%$ and $26.7 \%$, respectively. For Tianjin, the aggregation factor drove the increase in $\mathrm{EMR}_{\mathrm{PW}}$, whereas the sector structure factor impeded it. For Tangshan, the sector structure and aggregation factors both contributed to the increase in $\mathrm{EMR}_{\mathrm{PW}}$ by $59.9 \%$ and $40.1 \%$, respectively.

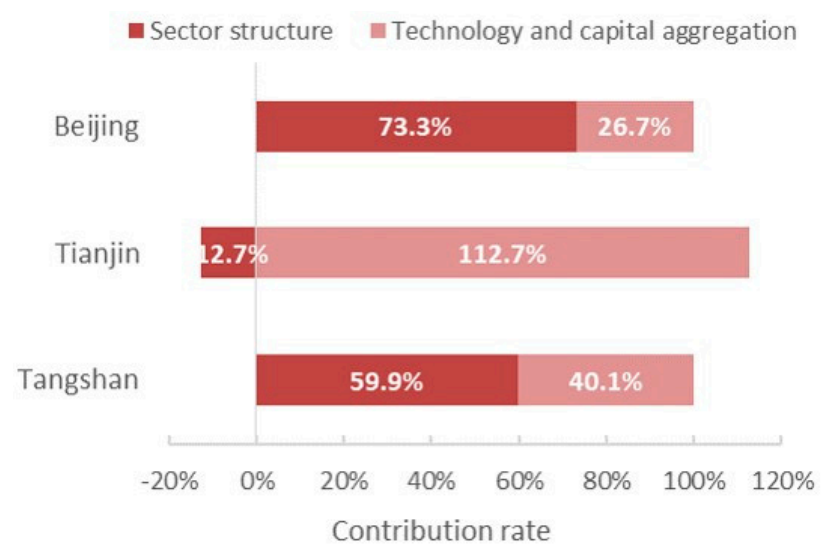

Figure 9. Contribution rates of technology and capital aggregation ( $\left.\mathrm{r}_{\text {aggregate }}\right)$ and sector structure $\left(r_{\text {structure }}\right)$ to the changes of EMR $R_{P W}$ in Beijing, Tianjin and Tangshan.

\subsection{Ecological Pressure and Social Welfare}

BEP and SOHA values from 2005 to 2014 were calculated, as shown in Table 5. BEP reflects the amount of energy that should be supplied by hourly human activity in the production sector, given the current level of energy consumption. The high value of BEP in one region indicates that people have to overexploit local resources and import energy externally to meet the material needs, which increases the pressure on the environment locally and regionally. From a temporal point of view, the BEP in the three cities exhibited an upward trend, except for Tangshan in 2014. Tangshan showed the highest BEP among the three cities because of the large proportion of energy-consuming sectors. Beijing ranked second due to the high standard of living and small proportion of primary and secondary sectors. By contrast, Tianjin had the lowest BEP among the three cities.

SOHA can be used to reflect the social welfare level. A higher SOHA value indicates that people can allocate more time to education, leisure and entertainment and lower dependency on labourers economically. The SOHA of Beijing increased from 5.5 in 2005 to 6.3 in 2009 and then became relatively 
constant later on. This higher value was consistent with the advanced education, good financial and technological foundations, high-quality human resources and high resource utilisation efficiency of Beijing. For Tianjin and Tangshan, their SOHA decreased from 5.8 in 2005 to 5.3 and 5.5 in 2014, respectively. This finding suggested that the two cities paid more attention to economic development than social welfare improvement.

Table 5. BEP and SOHA of Beijing, Tianjin and Tangshan.

\begin{tabular}{ccccccc}
\hline \multirow{2}{*}{ Year } & \multicolumn{3}{c}{ BEP $(\mathbf{M J} / \mathbf{h})$} & \multicolumn{3}{c}{ SOHA (h/h) } \\
\cline { 2 - 6 } & Beijing & Tianjin & Tangshan & Beijing & Tianjin & Tangshan \\
\hline 2005 & 233.0 & 156.6 & 262.3 & 5.5 & 5.8 & 5.8 \\
2006 & 258.4 & 170.9 & 295.0 & 5.4 & 6.0 & 5.8 \\
2007 & 284.8 & 179.8 & 335.7 & 5.8 & 5.6 & 6.0 \\
2008 & 313.8 & 194.3 & 362.0 & 6.0 & 5.8 & 6.0 \\
2009 & 335.2 & 205.4 & 361.7 & 6.2 & 5.7 & 5.7 \\
2010 & 335.5 & 218.6 & 383.0 & 6.2 & 5.5 & 5.5 \\
2011 & 330.8 & 242.5 & 409.6 & 6.1 & 5.5 & 5.6 \\
2012 & 350.3 & 252.0 & 413.2 & 6.1 & 5.4 & 5.5 \\
2013 & 333.6 & 254.7 & 429.3 & 6.0 & 5.3 & 5.5 \\
2014 & 343.3 & 243.7 & 347.6 & 6.0 & 5.3 & 5.5 \\
\hline
\end{tabular}

\section{Discussions}

\subsection{Comparison with Previous Studies}

MuSIASEM studies have been conducted in different cities, regions and nations for over 15 years. Table 6 summarises the results of 11 cases, including the three cities in this study. In comparison with the Chinese national average, Beijing, Tianjin, and Tangshan all had higher EMR $\mathrm{SA}_{\mathrm{S}}, \mathrm{ELP}_{\mathrm{PW}}$ and BEP, which coincided with their levels of economy and social development. However, the SOHA of Tianjin and Tangshan were slightly lower than the Chinese national average. The comparison of the three cities with other regions and countries in the world reveals that the EMR $\mathrm{SA}_{\mathrm{A}}$ of Tianjin in 2010 was similar with the level of the Catalonia region in 2005-which may be due to their well-established industrial foundation-whereas the EMR $\mathrm{EA}_{\mathrm{SA}}$ of Beijing in 2010 was similar to the level of the Veneto region in 2010. The ELP $\mathrm{PW}_{\mathrm{PW}}$ values of the three cities were considerably lower than those of the EU region, which might be explained by the relatively low economic efficiency and the abundant work forces in China. As shown in Table 6, the BEP values of the three cities were moderate compared to those of developed countries. However, the values of SOHA of the three cities were lower than those of other regions and countries. The phenomenon can be explained by the adoption of the one-child policy in China, which caused the high proportion of labour. However, the one-child policy will lead to the ageing of the population in the future and the emergence of inevitable labour shortage. Therefore, current economic growth patterns should be transformed to achieve sustainable development.

Table 6. Comparison of urban metabolism in Beijing, Tianjin, and Tangshan with other regions from previous studies.

\begin{tabular}{|c|c|c|c|c|c|c|}
\hline Urban/Region/Nation & $\begin{array}{c}\text { EMR }_{S A} \\
(\mathrm{MJ} / \mathrm{h})\end{array}$ & $\begin{array}{c}\text { ELP }_{P W} \\
\text { (US\$/h) }\end{array}$ & $\begin{array}{c}\text { BEP } \\
(\mathrm{MJ} / \mathrm{h})\end{array}$ & $\begin{array}{c}\text { SOHA } \\
(\mathbf{h} / \mathbf{h})\end{array}$ & Year of Study & Reference \\
\hline Beijing & 11.8 & 4.9 & 335.5 & 6.2 & 2010 & \\
\hline Tianjin & 17.5 & 4.7 & 218.6 & 5.5 & 2010 & \\
\hline Tangshan & 39.3 & 3.7 & 383.0 & 5.5 & 2010 & \\
\hline Shanghai & 16.2 & & 279.3 & & 2010 & {$[52]$} \\
\hline China & 8.6 & 1.8 & 86.6 & 5.6 & 2010 & {$[32]$} \\
\hline Veneto Region & 11.8 & 32.2 & 289.4 & 9.1 & 2007 & [34] \\
\hline Catalonia Region & 18.4 & 31.5 & 518.5 & 9.6 & 2005 & [25] \\
\hline Peru & 3.1 & 0.4 & 56.6 & 6.4 & 2010 & [29] \\
\hline UK & 18.7 & & 843.5 & 10.0 & 2004 & [24] \\
\hline Brazil & 5.2 & 4.3 & & 8.8 & 2000 & [29] \\
\hline AUSCAN (Australia, USA and Canada) & 38.8 & & & 8.6 & 1999 & [23] \\
\hline
\end{tabular}




\subsection{Urban Metabolism Profiles and Evolution Trajectories}

The classical four quadrants were employed to reveal the evolution of different urban metabolism in Beijing, Tianjin and Tangshan (Figures 10-12). The rightward horizontal line represents the TET (level $n$ ); the upward vertical line represents the THA (level $n$ ); the leftward horizontal line represents the $\mathrm{HA}_{\mathrm{PW}}$ (level $\left.n-1\right)$; the downward vertical line represents the $\mathrm{ET}_{\mathrm{PW}}$ (level $\left.n-1\right)$; and the orange and blue figures present the years 2005 and 2014, respectively.

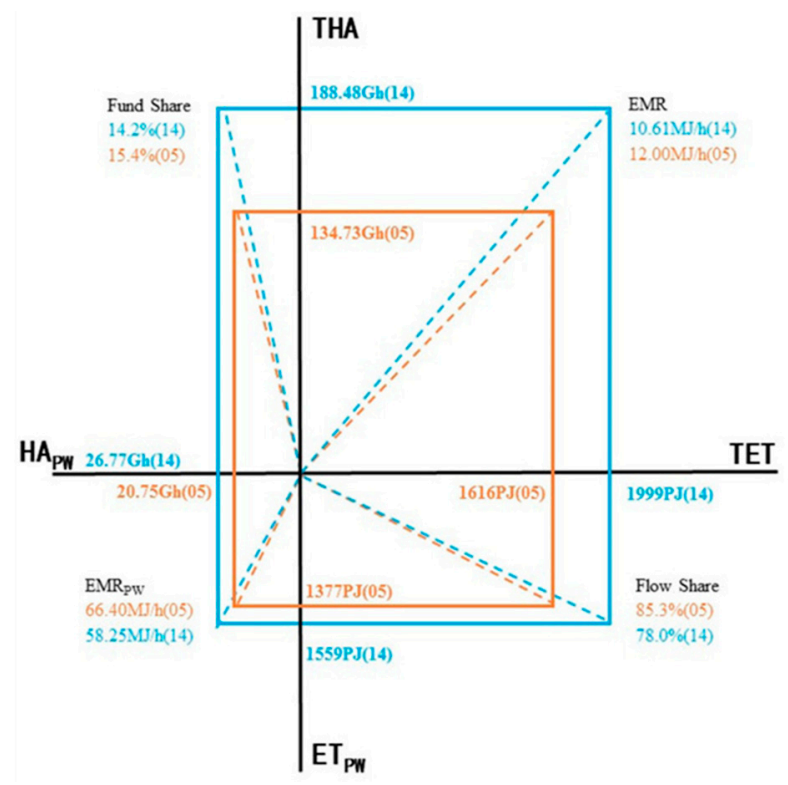

Figure 10. Flow-fund representation of MuSIASEM in Beijing for the years 2005 (orange) and 2014 (blue).

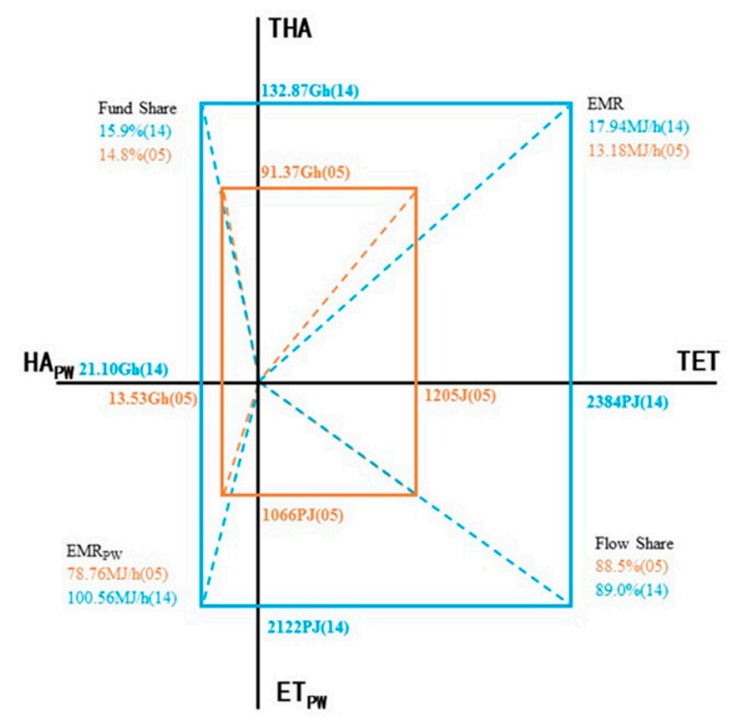

Figure 11. Flow-fund representation of MuSIASEM in Tianjin for the years 2005 (orange) and 2014 (blue). 


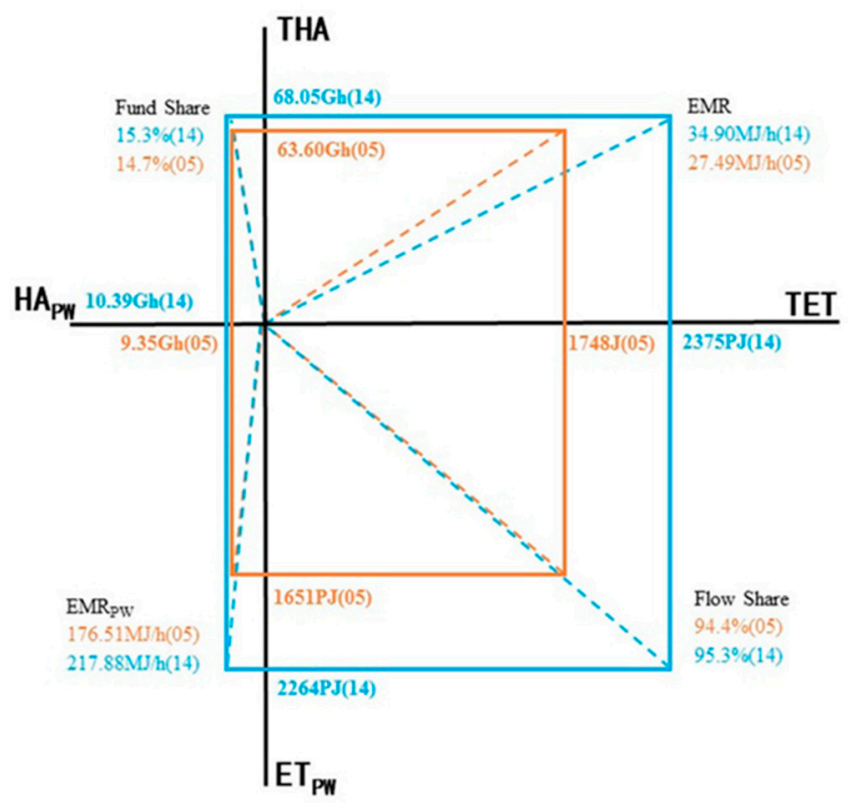

Figure 12. Flow-fund representation of MuSIASEM in Tianjin for the years 2005 (orange) and 2014 (blue).

\section{Beijing: Metabolic Pattern Dominated by Service}

With economic growth, Beijing increasingly attracted people to migrate to the city for better job opportunities. Simultaneously, more human activities were allocated to the $\mathrm{HH}$ sector, which not only indicated the improvement of social welfare but also led to the increase of the final energy consumption of the $\mathrm{HH}$ sector. Industrial upgrades and service sector development contributed to the reduction of $\mathrm{EMR}_{\mathrm{PW}}$ and the share of $\mathrm{ET}_{\mathrm{PW}}$. The metabolic pattern of Beijing was characterised by the developed service sector with population inflows, high SOHA, high $\mathrm{ELP}_{\mathrm{PW}}$, low EMR $\mathrm{PW}_{\mathrm{P}}$ and high BEP.

Tianjin: Metabolic Pattern Dominated by Technology and Capital Aggregation

Due to the increase in $\mathrm{EMR}_{\mathrm{PW}}$ and the share of $\mathrm{ET}_{\mathrm{PW}}$ over the analysis period, namely technology and capital aggregation, the growth of GDP and ELP $\mathrm{PW}_{\mathrm{W}}$ in Tianjin was the highest. Meanwhile, Tianjin experienced an economic structure transformation due to the increasing number of people moving to the service sector. This situation caused the share of $\mathrm{HA}_{\mathrm{PW}}$ to increase despite the technology and capital aggregation. The metabolic pattern of Tianjin was characterised as technology and capital aggregation with a high share of $\mathrm{ET}_{\mathrm{PW}}$, high $\mathrm{EMR}_{\mathrm{PW}}$, high $\mathrm{ELP}_{\mathrm{PW}}$ and low SOHA.

Tangshan: Metabolic Pattern Dominated by Traditional Industry

In Tangshan, the population was stable, but the TET was great and increasing. The high level of $\mathrm{EMR}_{\mathrm{PW}}$ and the high share of $\mathrm{ET}_{\mathrm{PW}}$ are some typical features of an industrial city. However, the high $\mathrm{EMR}_{\mathrm{PW}}$ was observed along with high ecological pressure (BEP) rather than high economic efficiency $\left(\mathrm{ELP}_{\mathrm{PW}}\right)$. Thus, the metabolic pattern of Tangshan was characterised by traditional industry with a high share of $\mathrm{ET}_{\mathrm{PW}}$, high $\mathrm{EMR}_{\mathrm{PW}}$, high $\mathrm{BEP}$ and low $\mathrm{ELP}_{\mathrm{PW}}$.

Figure 13 presents the evolution of urban metabolism based on ELP $\mathrm{PW}_{\mathrm{W}} \mathrm{BEP}$ and SOHA, which correspond to economic efficiency, ecological pressure and social welfare, respectively. The variables were normalised based on Z-score to compare the changes of the three variables with different units. As shown in Figure 13, economic efficiency, ecological pressure and social welfare increased simultaneously in Beijing. Tianjin performed best at economic efficiency but quite poorly at social welfare and moderately at ecological pressure. For Tangshan, the relatively low economic efficiency was obtained with an increase in ecological pressure and a decrease in social welfare. 


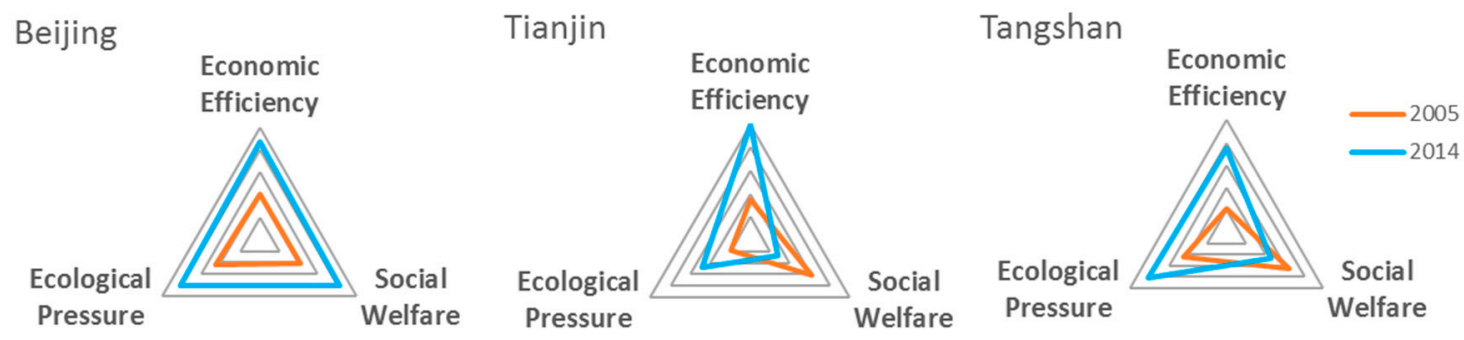

Figure 13. Evolution of urban metabolism in Beijing, Tianjin, and Tangshan.

The differing evolutions of the urban metabolism of the three cities were probably due to the different stages of their urban development. Based on the theories of Northam [53] and Kuznets [54], Beijing, Tianjin, and Tangshan were at three different stages of urban development. (1) Tangshan was at the intermediate stage of urbanisation and industrialisation. In this stage, the secondary industry played a leading role in the economy and was still characterised by energy intensive and low value added, which led to low economic efficiency and high ecological pressure. The growth of the economy depended on intensive labour. (2) Tianjin was at the late stage of urbanisation and the transition stage of industrialisation (from the intermediate stage to the late stage). In this period, the tertiary sector achieved rapid development and was as important as the secondary sector. At the same time, some technology and capital aggregations were observed in the secondary sector. Both factors contributed to good performances of economic efficiency. However, the development still depended on the increase in labour (both in number and in proportion) at the expense of social welfare (3). Beijing was at the late stage of urbanisation and industrialisation. In this phase, the tertiary sector became dominant in the economy and high-end manufacturing was a pillar industry in the secondary sector. Economic development no longer depended on intensive labour but on high technology, thereby improving social welfare. However, more human activities allocated to tertiary and $\mathrm{HH}$ sectors caused an increase in ecological pressure.

Combined with the dimensions of sustainable development, no problems were observed in the development dimensions because all three cities had increasing economic output and growing human activity to support it. However, in the coordination dimension, Tangshan performed poorly. All three cities faced challenges from the sustainability dimension due to increasing energy consumption and ecological pressure. Particularly, Tianjin and Tangshan suffered from the sustainability dimension because of the low level and decreased trend of social welfare.

\subsection{Relationships among Economic Growth, Energy Consumption and Ecological Pressure}

By comparing the changes of GDP and TET, positive correlations between the economic growth and energy consumption were found in all the three cities. The same conclusions were also drawn by the studies on China at national [55] and provincial levels [56]. The difference among the three cities was that the correlation coefficients of Tianjin and Tangshan were 0.970 and 0.989 , respectively, whereas that of Beijing was only 0.852. Similar differentiation also occurred in the East and South coasts of China [57]. Shanghai had slow growth in energy consumption and high levels of economic development, whereas the energy consumption and economic development of other provinces were rapidly increasing. The performances of Beijing and Shanghai were due to the stages of urban development where they were located, as previously discussed.

At the lower level $(n-1)$, an increase in $\operatorname{ELP}_{\mathrm{PW}}$ is usually accompanied by an increase in $\mathrm{EMR}_{\mathrm{PW}}$ [58], because the increase in EMR $\mathrm{PW}_{\mathrm{P}}$ suggests that more energy-dependent machines, rather than human labourers, are used. Although this explanation ignores the improvement of energy use efficiency, it was still applicable to Tianjin and Tangshan and to previous study areas such as Ecuador [21] and Spain [22]. By contrast, the diverging trend between $\mathrm{EMR}_{\mathrm{PW}}$ and $\mathrm{ELP}_{\mathrm{PW}}$ in Beijing implied that the city might be at the stage of dematerialisation in a certain extent for two reasons: 
(1) structural changes from energy-intensive sectors to non-energy-intensive sectors (e.g., service sector) and (2) improvements in energy efficiency. However, it may be not a real process of dematerialization because Beijing relocated the high-energy-consuming industries out of the city and still depended on energy from other areas. According to Zhang [59], the embodied energy import of Beijing was $1.3 \times 10^{12} \mathrm{MJ}$ in 2007 , which almost equalled $70.6 \%$ of the energy consumption of the city. This finding was consistent with the result of this study, because they both revealed that the BEP of Beijing was high.

\subsection{Policy Implications for Sustainability Development}

The distinctions between the different cities were evident from the results. Therefore, city managers should be aware of the different conditions of the three cities rather than make uniform policies to achieve sustainable development in the Jing-Jin-Ji urban agglomeration.

For Beijing, the population reached 21.2 million in 2014 [35]. Given the large immigrant population and great demand for labour in the service sector, the human activity allocated to the $\mathrm{HH}$ and service sectors also increased, which raised the demand of final consumption and BEP value. The amount of local resources in Beijing was limited. Thus, the dependency on external resources was increasing, which easily resulted in a so-called "siphon effect" - that is, the development of the central city restricts the development of the hinterland. Therefore, population control might be crucial for achieving sustainable development, at least in the short term. According to the Beijing City Master Plan (2016-2030), the Beijing government established the quota of permanent residents below 23.0 million by 2020 , which remains a serious challenge under the current trend. In the future, policies that encourage people and competitive industries to relocate-such as the establishment of the Xiong'an New Area-are recommended to mitigate the pressure of ecology and hopefully trigger "trickle-down effects" to where eventually the development of the central city benefits the hinterland.

According to the energy policy of the 13th Five-Year Plan for Economic and Social Development of the People's Republic of China (2016-2020), the energy consumption per 10,000 RMB of GDP in Beijing should decrease by $17.0 \%$. Achieving this goal based on the current trend is not difficult-the annual rate of decline was $5.14 \%$ during the analysis period-and people should consider the energy utilisation efficiency in the $\mathrm{HH}$ sector.

In Tianjin, labour efficiency is the highest among the three cities because of technology and capital aggregation and industrial structure upgrades. Nevertheless, the percentage of human activity of the PW sector in Tianjin still increased, which suggests that the economic development was dependent on increasing the proportion of labourers at the expense of social welfare. Therefore, in the short term, the local government should create policies that will attract more young people to live in Tianjin to prevent a labour shortage caused by the ageing population. In the long term, economic growth patterns should be transformed to raise the level of mechanisation, as well as adjust its industrial structure to acquire higher ELP. The ELP $\mathrm{PW}_{\mathrm{PW}}$ of Tianjin should increase to at least US $\$ 7.3 / \mathrm{h}$ in order to match the current social welfare level of Beijing. Meanwhile, more social welfare-related polices—such as better education, health care and insurance policies for the elderly-should be encouraged.

To meet the target for energy consumption per 10,000 RMB of GDP to be lowered to $1.0 \times 10^{4} \mathrm{MJ}$ in 2030 year (Tianjin City Master Plan 2015-2030), it is suggested that Tianjin focuses more on saving energy in the secondary sector, especially in metallurgical, power, chemical and petrochemical industries.

As a traditional industry city, Tangshan is facing two major challenges towards sustainability: the great energy consumption of the secondary sector and the low economic competitiveness of the PW sector-in other words, low efficiency of energy and labour. As a result, Tangshan showed the highest $\mathrm{BEP}$ and lowest ELP $\mathrm{PW}$ among the three cities. According to the Tangshan City Master Plan (2010-2020), Tangshan has established a goal that the energy consumption per 10,000 RMB of GDP should lower to $3.9 \times 10^{4} \mathrm{MJ}$ by 2020, which could be challenging given that the consumption level was still $4.6 \times 10^{4} \mathrm{MJ}$ in 2014. Thus, the government should encourage enterprises to adopt technologies that can reduce energy consumption and support the promotion of renewable and clean energy—such 
as wind, solar and nuclear power-to ease ecological pressure. Additionally, finding ways to accelerate industrial upgrading is essential, such as gradually removing industries with low added value and undertaking industries with high technology and high added value from Beijing.

One limitation of this research is that land use was not incorporated into the framework due to the lack of long time series data of land use that could clearly separate industrial, service and residential lands. In future research, land use data with a high resolution should be obtained to study the economic efficiency of different land use types, the proportion of different land use types and the relationships between human activity and land use in different sectors. Moreover, the inequalities within the urban population have recently drawn considerable attention in urban sustainable development research $[60,61]$. Further research on urban metabolism is necessary to reveal the inequalities among different income groups.

\section{Conclusions}

This research used the MuSIASEM framework as a diagnostic tool to reveal the metabolic characteristics and evolution trajectories in the Chinese cities of Beijing, Tianjin, and Tangshan. First, the metabolic pattern and evolution trajectories of Beijing, Tianjin, and Tangshan were found to be service-dominated, technology and capital aggregation-dominated and traditional industry-dominated, respectively. Moreover, the evolution of economic efficiency, ecological pressure and social welfare in the three cities was different due to the stage of urban development at which each city is located. The aggregation and sector structure factors caused the reduction and increment of the EMR $\mathrm{PW}_{\mathrm{P}}$ in Beijing and Tangshan, respectively. Nevertheless, the increase in $\mathrm{EMR}_{\mathrm{PW}}$ in Tianjin was driven by the aggregation factor and partly offset by the sector structure factor. Secondly, in terms of the relationships between economic growth and energy consumption, Tianjin and Tangshan showed positive correlations at the city level and PW sector level, whereas Beijing demonstrated a weaker positive correlation. Thirdly, issues such as overpopulation, labour shortage and low efficiency of energy and labour are likely to be the key factors that impede the sustainable development of the three cities in the future. On the basis of these results, several policy implications were raised, including combining the population dispersal and competitive industry relocation policies for Beijing, attracting more young labourers in the short term and transforming the economic growth patterns in the long term for Tianjin, and upgrading industry and innovating technical processes for Tangshan. Further studies are recommended to incorporate land use data into the MuSIASEM framework and to consider the inequalities within the urban population for better urban management.

Acknowledgments: This research was supported by the Major Projects of the National Natural Science Foundation of China (No. 41590843).

Author Contributions: Xiaoyue Wang designed the study and wrote the paper, and Shuyao Wu and Shuangcheng Li revised the paper. All authors read and approved the final manuscript.

Conflicts of Interest: The authors declare no conflict of interest.

\section{References}

1. The United Nations Environment Programme. Global Initiative for Resource efficient Cities: Engine to Sustainability. Available online: http://gallery.mailchimp.com/ca9c1fdc492e0cdf6766c8a26/files/GI_REC_ flyer_4pager_EN_CF.pdf (accessed on 3 March 2017).

2. 2014 Revision of the World Urbanization Prospects. Available online: http:/ / www.un.org/en/development/ desa/publications / 2014-revision-world-urbanization-prospects.html (accessed on 1 March 2017).

3. Wolman, A. The Metabolism of Cities. Sci. Am. 1965, 213, 179. [CrossRef] [PubMed]

4. Kennedy, C.; Cuddihy, J.; Engel-Yan, J. The changing metabolism of cities. J. Ind. Ecol. 2007, 11, 43-59. [CrossRef]

5. Kennedy, C.; Pincetl, S.; Bunje, P. The study of urban metabolism and its applications to urban planning and design. Environ. Pollut. 2011, 159, 1965-1973. [CrossRef] [PubMed] 
6. Zhang, Y. Urban metabolism: A review of research methodologies. Environ. Pollut. 2013, 178, 463. [CrossRef] [PubMed]

7. Rosado, L.; Kalmykova, Y.; Patrício, J. Urban metabolism profiles. An empirical analysis of the material flow characteristics of three metropolitan areas in Sweden. J. Clean. Prod. 2016, 126, 206-217. [CrossRef]

8. Lee, S.E.; Quinn, A.D.; Rogers, C.D. Advancing City Sustainability via Its Systems of Flows: The Urban Metabolism of Birmingham and Its Hinterland. Sustainability 2016, 8, 220. [CrossRef]

9. Liu, C.; Shi, X.; Qu, L.; Li, B. Comparative analysis for the urban metabolic differences of two types of cities in the resource-dependent region based on emergy theory. Sustainability 2016, 8, 635. [CrossRef]

10. Sun, L.; Dong, H.; Geng, Y.; Li, Z.; Liu, Z.; Fujita, T.; Ohnishi, S.; Fujii, M. Uncovering driving forces on urban metabolism-A case of Shenyang. J. Clean. Prod. 2016, 114, 171-179. [CrossRef]

11. Moore, J.; Kissinger, M.; Rees, W.E. An urban metabolism and ecological footprint assessment of Metro Vancouver. J. Environ. Manag. 2013, 124, 51. [CrossRef] [PubMed]

12. Geng, Y.; Zhang, L.; Chen, X.; Xue, B.; Fujita, T.; Dong, H. Urban ecological footprint analysis: A comparative study between Shenyang in China and Kawasaki in Japan. J. Clean. Prod. 2014, 75, 130-142. [CrossRef]

13. Giampietro, M.; Mayumi, K. A dynamic model of socioeconomic systems based on hierarchy theory and its application to sustainability. Struct. Chang. Econ. Dyn. 1997, 8, 453-469. [CrossRef]

14. Giampietro, M.; Mayumi, K. Multiple-Scale Integrated Assessment of Societal Metabolism: Introducing the Approach. Popul. Environ. 2000, 22, 109-153. [CrossRef]

15. Giampietro, M.; Mayumi, K. Multiple-Scale Integrated Assessments of Societal Metabolism: Integrating Biophysical and Economic Representations across Scales. Popul. Environ. 2000, 22, 155-210. [CrossRef]

16. Pastore, G.; Giampietro, M.; Mayumi, K. Societal Metabolism and Multiple-Scale Integrated Assessment: Empirical Validation and Examples of Application. Popul. Environ. 2000, 22, 211-254. [CrossRef]

17. Giampietro, M.; Mayumi, K.; Bukkens, S.G.F. Multiple-Scale Integrated Assessment of Societal Metabolism: An Analytical Tool to Study Development and Sustainability. Environ. Dev. Sustain. 2001, 3, $275-307$. [CrossRef]

18. Giampietro, M.; Mayumi, K.; Ramos-Martin, J. Multi-scale integrated analysis of societal and ecosystem metabolism (MuSIASEM): Theoretical concepts and basic rationale. Energy 2009, 34, 313-322. [CrossRef]

19. Sorman, A.H.; Giampietro, M. Generating better energy indicators: Addressing the existence of multiple scales and multiple dimensions. Ecol. Model. 2011, 223, 41-53. [CrossRef]

20. Giampietro, M.; Bukkens, S.G.F. Analogy between Sudoku and the multi-scale integrated analysis of societal metabolism. Ecol. Inf. 2015, 26, 18-28. [CrossRef]

21. Falconí-Benítez, F. Integrated Assessment of the Recent Economic History of Ecuador. Popul. Environ. 2001, 22, 257-280. [CrossRef]

22. Ramos-Martín, J. Historical Analysis of Energy Intensity of Spain: From a "Conventional View" to an “Integrated Assessment". Popul. Environ. 2001, 22, 281-313. [CrossRef]

23. Ramos-Martin, J.; Giampietro, M.; Mayumi, K. On China's exosomatic energy metabolism: An application of multi-scale integrated analysis of societal metabolism (MSIASM). Ecol. Econ. 2007, 63, 174-191. [CrossRef]

24. Gasparatos, A.; El-Haram, M.; Horner, M. Assessing the sustainability of the UK society using thermodynamic concepts: Part 1. Renew. Sustain. Energy Rev. 2009, 13, 1074-1081. [CrossRef]

25. Ramos-Martín, J.; Cañellas-Boltà, S.; Giampietro, M.; Gamboa, G. Catalonia's energy metabolism: Using the MuSIASEM approach at different scales. Energy Policy 2009, 37, 4658-4671. [CrossRef]

26. Ariza-Montobbio, P.; Farrell, K.N.; Gamboa, G.; Ramos-Martin, J. Integrating energy and land-use planning: Socio-metabolic profiles along the rural-urban continuum in Catalonia (Spain). Environ. Dev. Sustain. 2014, 16, 925-956. [CrossRef]

27. Lobo Aleu, A.; Baeza, M.Á. A First Attempt of Geographically-Distributed Multi-Scale Integrated Analysis of Societal and Ecosystem Metabolism (MuSIASEM); Institut de Ciència i Tecnologia Ambientals (ICTA-UAB): Barcelona, Spain, 2009.

28. Lu, Y.; Geng, Y.; Qian, Y.; Han, W.; Mcdowall, W.; Bleischwitz, R. Changes of human time and land use pattern in one mega city's urban metabolism: A multi-scale integrated analysis of Shanghai. J. Clean. Prod. 2016, 133, 391-401. [CrossRef]

29. Silva-Macher, J.C. A Metabolic Profile of Peru: An Application of Multi-Scale Integrated Analysis of Societal and Ecosystem Metabolism (MuSIASEM) to the Mining Sector's Exosomatic Energy Flows. J. Ind. Ecol. 2016, 20, 1072-1082. [CrossRef] 
30. Gomiero, T.; Giampietro, M. Multiple-Scale Integrated Analysis of Farming Systems: The Thuong Lo Commune (Vietnamese Uplands) Case Study. Popul. Environ. 2001, 22, 315-352. [CrossRef]

31. Iorgulescu, R.I.; Polimeni, J.M. A multi-scale integrated analysis of the energy use in Romania, Bulgaria, Poland and Hungary. Energy 2009, 34, 341-347. [CrossRef]

32. Velasco-Fernández, R.; Ramos-Martín, J.; Giampietro, M. The energy metabolism of China and India between 1971 and 2010: Studying the bifurcation. Renew. Sustain. Energy Rev. 2015, 41, 1052-1066. [CrossRef]

33. Geng, Y.; Liu, Y.; Liu, D.; Zhao, H.; Xue, B. Regional societal and ecosystem metabolism analysis in China: A multi-scale integrated analysis of societal metabolism(MSIASM) approach. Energy 2011, 36, 4799-4808. [CrossRef]

34. Siciliano, G.; Crociata, A.; Turvani, M. A Multi-level Integrated Analysis of Socio-Economic Systems Metabolism: An Application to the Italian Regional Level. Environ. Policy Gov. 2012, 22, 350-368. [CrossRef]

35. China Statistical Yearbook 2015. Available online: http://www.stats.gov.cn/tjsj/ndsj/2015/indexeh.htm (accessed on 20 November 2016).

36. Beijing Statistical Yearbook 2015. Available online: http://www.stats.gov.cn/tjsj/ndsj/2015/indexeh.htm (accessed on 20 November 2016).

37. Beijing Statistical Yearbook 2013. Available online: http://www.bjstats.gov.cn/nj/main/2013_ch/index.htm (accessed on 20 November 2016).

38. Tianjin Statistical Yearbook 2015. Available online: http://www.stats-tj.gov.cn/Item/25712.aspx (accessed on 21 November 2016).

39. Tangshan Statistical Yearbook 2015. Available online: http://nianjian.xiaze.com/down/2016/tangshantjnjxls-2015.html (accessed on 22 November 2016).

40. Fischer-Kowalski, M. Society's metabolism. J. Ind. Ecol. 1998, 2, 61-78. [CrossRef]

41. Lotka, A.J. Elements of Mathematical Biology; Dover Publications Inc.: New York, NY, USA, 1956.

42. Nicholas, G.-R. The Entropy Law and the Economic Process; Harvard University Press: Cambridge, MA, USA, 1971.

43. Ulanowicz, R.E. Growth and Development: Ecosystems Phenomenology; Springer Science \& Business Media: Berlin, Germany, 2012.

44. Odum, E.P.; Odum, H.T.; Andrews, J. Fundamentals of Ecology; Saunders: Philadelphia, PA, USA, 1971; Volume 3.

45. Kingsley Zipf, G. National Unity and Disunity. (Scientific Books: National Unity and Disunity). Science 1941, $94,19$.

46. Hall, C.A.; Cleveland, C.J.; Kaufmann, R.K.; Behler, D. Energy and Resource Quality: The Ecology of the Economic Process; Saunders: Philadelphia, PA, USA, 1986.

47. World Commission on Environment. Our Common Future; Oxford University Press: Oxford, UK, 1987.

48. Serageldin, I. Making development sustainable. Financ. Dev. 1993, $30,6$.

49. Eisenmenger, N.; Giljum, S. Evidence from societal metabolism studies for ecological unequal trade. In The World System and the Earth System: Global Socioenvironmental Change and Sustainability Since the Neolithic; Left Coast Press: Walnut Creek, CA, USA, 2007; pp. 288-302.

50. Niu, W. The Overview of China's Sustainable Development; Science Press: Beijing, China, 2012.

51. Sun, J. Changes in energy consumption and energy intensity: A complete decomposition model. Energy Econ. 1998, 20, 85-100. [CrossRef]

52. Dai, G.Y.; Jiao, L. A Societal Metabolism Analysis of Shanghai Based on MSIASM Theory and Carbon Emissions from Energy Consumption. Shanghai Environ. Sci. 2013, 32, 254-270.

53. Northam, R.M. Urban Geography; John Wiley and Sons: New York, NY, USA, 1979.

54. Kuznets, S. Quantitative aspects of the economic growth of nations: II. industrial distribution of national product and labor force. Econ. Dev. Cult. Chang. 1957, 5, 1-111. [CrossRef]

55. Qiang, W. Effects of urbanisation on energy consumption in China. Energy Policy 2014, 65, 332-339.

56. Wang, Q.; Zeng, Y.-E.; Wu, B.-W. Exploring the relationship between urbanization, energy consumption, and $\mathrm{CO}_{2}$ emissions in different provinces of China. Renew. Sustain. Energy Rev. 2016, 54, 1563-1579. [CrossRef]

57. Gao, C.; Liu, Y.; Jin, J.; Wei, T.; Zhang, J.; Zhu, L. Driving forces in energy-related carbon dioxide emissions in east and south coastal China: Commonality and variations. J. Clean. Prod. 2016, 135, 240-250. [CrossRef]

58. Cleveland, C.J.; Costanza, R.; Hall, C.A.; Kaufmann, R. Energy and the u.s. Economy: A biophysical perspective. Science 1984, 225, 890-897. [CrossRef] [PubMed] 
59. Zhang, Y.; Zheng, H.; Yang, Z.; Li, Y.; Liu, G.; Su, M.; Yin, X. Urban energy flow processes in the Beijing-Tianjin-Hebei (Jing-Jin-Ji) urban agglomeration: Combining multi-regional input-output tables with ecological network analysis. J. Clean. Prod. 2016, 114, 243-256. [CrossRef]

60. Wiedenhofer, D.; Guan, D.; Liu, Z.; Meng, J.; Zhang, N.; Wei, Y.M. Unequal household carbon footprints in China. Nat. Clim. Chang. 2017, 7, 75-80. [CrossRef]

61. Brelsford, C.; Lobo, J.; Hand, J.; Lma, B. Heterogeneity and scale of sustainable development in cities. Proc. Natl. Acad. Sci. USA 2017, 201606033. [CrossRef] [PubMed]

C 2017 by the authors. Licensee MDPI, Basel, Switzerland. This article is an open access article distributed under the terms and conditions of the Creative Commons Attribution (CC BY) license (http://creativecommons.org/licenses/by/4.0/). 